\title{
Rock Stress Measurements for Unlined Pressure Tunnels: A True Triaxial Laboratory Experiment to Investigate the Ability of a Simplified Hydraulic Jacking Test to Assess Fracture Normal Stress
}

\author{
Henki Ødegaard' ${ }^{1}$ (1) Bjørn Nilsen ${ }^{1}$
}

Received: 23 October 2020 / Accepted: 19 March 2021 / Published online: 27 March 2021

(c) The Author(s) 2021

\begin{abstract}
To avoid hydraulic failure of unlined pressure tunnels, knowledge of minimum principal stress is needed. Such knowledge is only obtainable from in situ measurements, which are often time-consuming and relatively costly, effectively limiting the number of measurements typically performed. In an effort to enable more stress measurements, the authors propose a simplified and cost-effective stress measuring method; the Rapid Step-Rate Test (RSRT), which is based on existing hydraulic testing methods. To investigate the ability of this test to measure fracture normal stresses in field-like conditions, a true triaxial laboratory test rig has been developed. Hydraulic jacking experiments performed on four granite specimens, each containing a fracture, have been performed. Interpretation of pressure-, flow- and acoustic emission (AE) data has been used to interpret fracture behaviour and to assess fracture normal stresses. Our experimental data suggest that the proposed test method, to a satisfactory degree of reliability, can measure the magnitude of fracture normal stress. In addition, a clear correlation has been found between fracture closure and sudden increase in $\mathrm{AE}$ rate, suggesting that $\mathrm{AE}$ monitoring during testing can serve as a useful addition to the test. The rapid step-rate test is also considered relevant for field-scale measurements, with only minor adaptions. Our findings suggest that the RSRT can represent a way to get closer to the ideal of performing more testing along the entire length of pressure tunnel, and not only at key locations, which requires interpolation of stress data with varying degree of validity.
\end{abstract}

Keywords Hydropower $\cdot$ Unlined pressure tunnels $\cdot$ Hydraulic jacking $\cdot$ Rock stress measurements $\cdot$ True-triaxial testing

\section{Introduction}

The main objective of experiments described in this paper is linked to a general challenge encountered during final design of pressure tunnels in hydropower; how can the magnitude of minimum principal rock stress be assessed, to a satisfactory degree of reliability, along several kilometres of unlined pressure tunnel? In the early 1900 s, prior to the establishment of reliable methods for measuring the underground state of stress, engineers designing the first pressure tunnels made their stress estimations based on simple calculation of overburden weight, as described by Schjerven (1921) and Berkey and Sanborn (1922). This approach,

Henki Ødegaard

henki.odegaard@ntnu.no

1 Norwegian University of Science and Technology, Trondheim, Norway assuming a nearly hydrostatic stress field with all three principal stresses similar and corresponding to the overburden weight is not generally true-as convincingly demonstrated in the landmark paper written by Hubbert and Willis (1957). Still, as thoroughly described in Rancourt (2010), the tradition of using overburden weight as input for stress estimation, the so-called overburden criteria, persists in various design guidelines. Though useful for preliminary assessment of rock stress, overburden criteria in general suffer from assumptions and over-simplifications making them unsuitable for reliable estimate of minimum principal stress (USACE 1997; Merritt 1999; Rancourt 2010).

Today, it is generally accepted that reliable data on the magnitude of minimum principal rock stress is absolutely required to ensure a safe design of unlined pressure tunnels, and that in situ stress measurements are essential in providing such information. In connection with investigations for unlined pressure tunnels, hydraulic fracturing (HF) and hydraulic testing of pre-existing fractures (HTPF) have 
become common test methods. These tests, both standardized by the ISRM (Haimson and Cornet 2003), can under ideal testing conditions provide highly reliable estimates of the magnitude of minimum principal stress. Still, the relatively high testing cost, combined with the economical sensitivity of most hydropower projects, limit the number of tests that can be justified, often leaving long stretches of the pressure tunnel essentially untested. In some extreme cases, stress measurements are omitted altogether and design is based on empirical overburden criteria alone. This is indeed a risky approach, as experienced for instance in the recent failure of the Bjørnstokk HPP in Norway (Nordal et al. 2018).

To mitigate some of the risk associated with the current practice of performing few, but high quality, measurements at test locations relatively far apart, often requiring stress interpolation of uncertain validity, the authors believe it is required to distribute measurement locations and at the same time increase the number of measurement locations. For such an approach to be practically and economically viable, stress measurements need to be cost-effective, relatively fast and uncomplicated to execute, with a minimum requirement for specialized equipment and crew. Various types of hydraulic jacking tests have been performed regularly by parties engaged in the final design of unlined pressure tunnels both in Norway and abroad. These tests are typically borehole tests where existing fractures of unknown orientation are hydraulically stimulated to find the pressure at which the fracture opens, slips (if it supports some amount of shear stress) and closes. The basic idea behind performing such hydraulic jacking tests is to find the population of fractures oriented perpendicularly to the minimum principal stress, $\sigma_{3}$. This requires a large number of tests, performed in boreholes of various orientations. The lower bound values obtained from these tests in a given volume of rock is considered representative of the minimum principal stress (Hartmaier et al. 1998). The main advantage of this approach is the relatively large number of individual measurements, providing better insight into the stress variability, and potentially detecting regions of lower than expected stresses, rather than the absolute accuracy of which the minimum principal stress can be measured.

Based on the authors involvement in stress measurements for many hydroelectric projects, with observation of various challenges encountered with the execution and interpretation of hydraulic jacking tests, we have designed a laboratory experiment to investigate the ability of hydraulic jacking tests to measure fracture normal stress. Two variants of hydraulic jacking tests have been tested as part of this study and are presented in Sect. 4.1. Both test types are inspired by existing hydraulic jacking test methods but are still novel by the simplification of test procedure, limiting the requirements of specialized

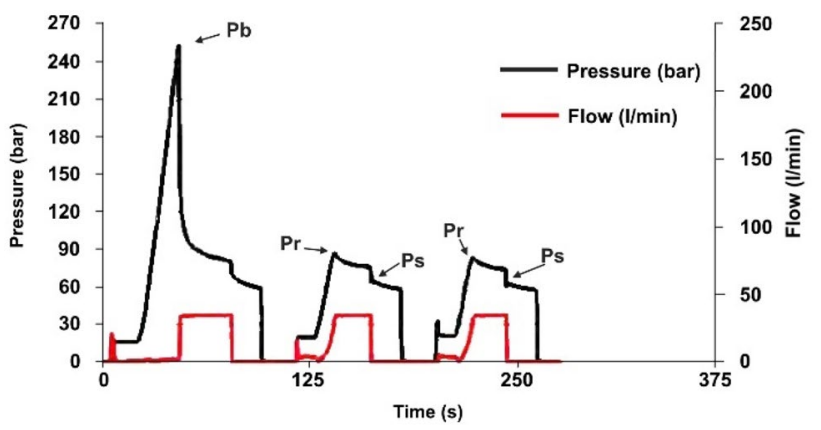

Fig. 1 Typical pressure-time curve obtained from a HF test conducted as part of the investigations for a Norwegian hydroelectric plant. (Average $P_{\mathrm{s}}$ from the two reopening cycles was interpreted at 69 bars)

crew and equipment. To make the laboratory experiments as representative as possible for in situ testing conditions, efforts have been made to ensure that conditions in the lab closely resemble what is common in the field, including true triaxial confinement of the tested rock specimens.

Laboratory scale hydraulic fracturing experiments under true triaxial confinement have been widely studied by researchers working in the petroleum industry (Haimson and Fairhurst 1969; Ishida et al. 1997; Chitrala et al. 2011; Rasouli 2013; Stanchits et al. 2014; Huang and Liu 2017), by researchers working with deep geothermal projects (Frash et al. 2015; Hampton et al. 2018; Zhuang et al. 2020), and for field-scale rock stress measurements (Ikeda and Tsukahara 1982; Cheung and Haimson 1989; Ishida 2001). The study described in this paper is, to the authors' knowledge, the first time that laboratory-scale hydraulic fracturing experiments under true triaxial confinement have been used in connection with investigations for design of unlined hydropower tunnels.

\section{Conventional Hydraulic Tests for Measuring the Underground State of Stress}

\subsection{Hydraulic Fracturing}

The HF test method includes the pressurization, usually by water, of a short, isolated section of borehole, devoid of fractures, until a fracture is created. The pressures at which the borehole ruptures, termed the breakdown pressure $\left(P_{\mathrm{b}}\right)$, the pressure required to reopen the fracture at consecutive pressure cycles $\left(P_{\mathrm{r}}\right)$ and the pressure measured immediately after pumping stops, termed the instantaneous shut-in pressure $\left(P_{\mathrm{s}}\right)$ are all recorded throughout the test, see Fig. 1. 
The in situ state of stress can be assessed from such measurements by applying the classical hydraulic fracturing criterion, introduced by Hubbert and Willis (1957):

$P_{\mathrm{b}}=T+3 \sigma_{3}-\sigma_{1}-P_{0}$

or

$\sigma_{1}=T+3 \sigma_{3}-P_{\mathrm{b}}-P_{0}$

where $T$ is the tensile strength of the rock, $P_{0}$ the initial pore pressure in the rock and $\sigma_{1}$ and $\sigma_{3}$ are the maximum and minimum principal stresses, respectively. Guidelines on how to measure the tensile strength of the rock, $T$, are provided in Haimson and Cornet (2003), including laboratory tests on extracted core, such as the hollow cylinder test or the Brazilian test, or, when core is not available, by looking at the difference between breakdown pressure in the first pressure cycle, $P_{\mathrm{b}}$, and the reopening pressure, $P_{\mathrm{r}}$, found during subsequent cycles.

Calculation of the magnitude of $\sigma_{1}$ based on Eq. (1) has proven rather uncertain due to the difficulty in assessing the tensile strength from such tests (Zoback 2007). Magnitude of $\sigma_{3}$, however, require no calculation since in the classical interpretation of the HF test, it is assumed that the created fracture opens normal to the minimum principal stress, and consequently that:

$P_{\mathrm{s}}=\sigma_{3}$

Several techniques for assessing the minimum principal stress from analysis of hydraulic fracturing tests are described in the literature, and reference is made to Zoback and Kohli (2019) for an overview of such methods.

When a fracture has been created, it can be assumed that for consecutive pressurization cycles $T=0$, and that $P_{\mathrm{b}}$ in Eq. (1) can be replaced by the reopening pressure, $P_{\mathrm{r}}$ such that (Bredehoeft et al. 1976):

$P_{\mathrm{r}}=3 \sigma_{3}-\sigma_{1}-P_{0}$

or

$\sigma_{1}=3 P_{\mathrm{s}}-P_{\mathrm{r}}-P_{0}$

There is also some uncertainty related to this method of calculating $\sigma_{1}$, mainly due to the difficulty of picking the exact pressure at which the fracture re-opens (Ito et al. 1999). In addition, in cases with negative tangential stresses around the borehole, i.e. where $3 \sigma_{3}<\sigma_{1}$, the fracture will never completely close, and no meaningful estimate on reopening pressures can be identified (Haimson 1992).

An important requirement for the proper execution and interpretation of the HF test is that the borehole axis is in the same direction as one of the principal stresses, or at least deviating less than $15^{\circ}$ from it. Tests performed in deviating boreholes invalidate the classical method of interpreting results, potentially causing considerable error (Warren and Smith 1985). This requirement necessitates, in principle, reliable information of the stress directions, which for hydroelectric projects-often situated at relatively shallow depths in mountainous regions, would require 3D stress measurements since the in situ stress orientation might vary considerably over short distances. The additional cost and time required for 3D stress measurements limit the applicability of the HF test in such cases.

\subsection{Hydraulic Testing of Pre-existing Fractures}

To circumvent some of the limitations associated with the HF method, the HTPF test was developed by Cornet and Valette (1984). The objective of the HTPF method is to determine the normal stress supported by pre-existing fracture planes with known orientations and, by inversion of the test results, determining the complete stress field.

The magnitude of normal stress is found in much the same way as done for assessing $\sigma_{3}$ during the HF test, i.e. by assessing shut-in pressure after full fracture opening. However, since the stimulated fracture is not necessarily oriented normal to $\sigma_{3}$, Eq. (2) can be rewritten as follows: $P_{\mathrm{s}}=\sigma_{\mathrm{n}}$

where $\sigma_{\mathrm{n}}$ is the normal stress acting across the fracture. The HTPF test is performed by pressurizing the test section at a pre-determined constant flow until fracture opening, followed by a shut-in phase, similar to the HF test. After this first cycle is either: (1) a stepwise increase (forward-step) in flow rate conducted until full fracture opening, followed by another shut-in phase; or (2) an initial forward-step flow increase followed by a stepwise flow decrease (backwardstep). By plotting pressure data vs. flow rate from the steprate tests can a bilinear curve be obtained, the intersection of which can be taken as the normal stress (Haimson and Cornet 2003). Determining the regional stress field is then done by finding a best fit function to the measured normal stresses, together with the fracture orientation, as presented by Cornet (1993).

Testing a minimum of eight individual fractures of various orientation is required for a complete stress determination with the HTPF test. Since each tested fracture needs to be isolated it is further a requirement that the rock mass cannot be too fractured (Amadei and Stephansson 1997). The number of tests required can, however, be reduced by combining the HF test with the HTPF test, provided ideal testing conditions (Cornet 2016). The relatively large number of tests combined with the extensive formulae required to find the complete stress field is arguably 
Fig. 2 Schematic view of a borehole intersected by a fracture supporting a normal stress $\sigma_{\mathrm{n}}$ at various stages of the hydraulic jacking test. a Installation of single packer at predetermined depth, b pressurization of the test section, with the corresponding, idealized, linear trend in the $q P_{\text {inj-plot, }} \mathbf{c}$ onset of hydraulic jacking of the fracture, indicated by the transition between linear to gradual $q P_{\text {inj }}$ development to the right and $\mathbf{d}$ full hydraulic jacking
A

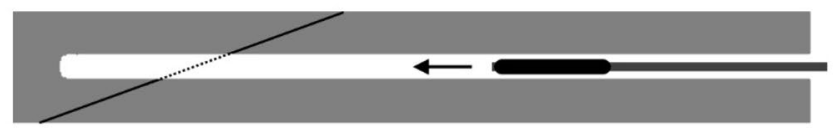

B
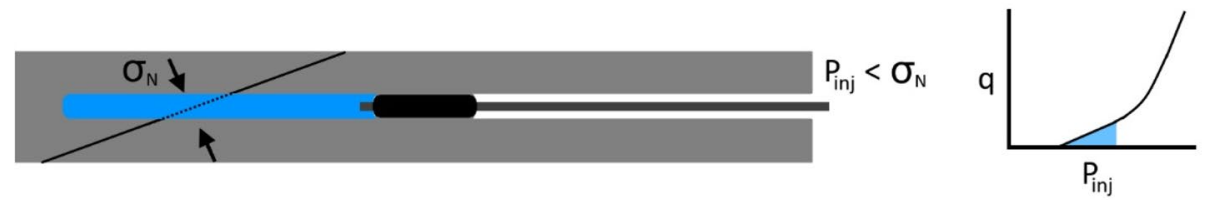

C
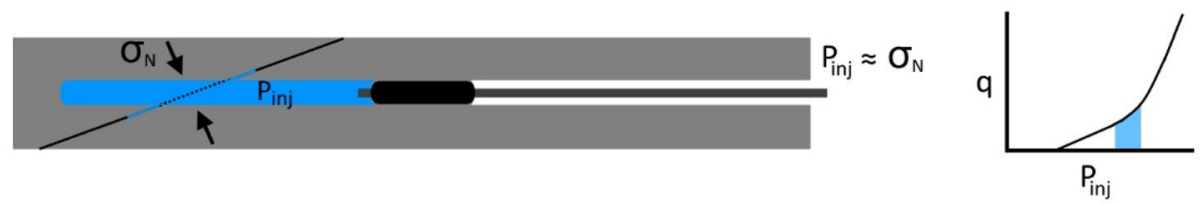

D

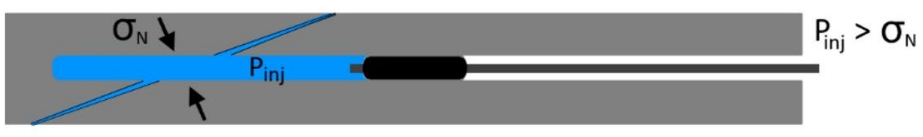

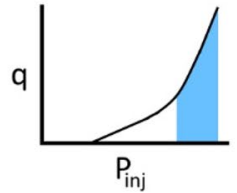

the main drawback of the HTPF method in the context of assessing $\sigma_{3}$ for unlined pressure tunnel design purposes.

\subsection{Hydraulic Jacking Tests}

The basic principle of the various hydraulic jacking tests is to pressurize a section of a borehole intersected by one or several pre-existing fractures, and by monitoring fluid pressure and flow to find the fluid pressure at which the fracture can be kept opened. This pressure is taken as a measure of the normal stress acting across the stimulated fracture, since once the fracture is opened, the stress concentration which previously surrounded the borehole is reduced and the pressure, $P_{\text {inj }}$, required to hold the fracture open is equal to that of the in situ normal stress across the fracture (Hubbert and Willis 1957).

According to Rutqvist and Stephansson (2003), the first hydraulic jacking tests were performed during the investigation of the Malpasset dam failure in the 1960s. During these investigations, it was demonstrated how the permeability of the rock mass was affected by the effective normal stresses on the fractures, with permeability decreasing with increasing effective stress (Londe and Sabarly 1966). These tests thus provided some of the first insights on the hydromechanical (HM) coupling in fractured rock masses. Many variants of hydraulic jacking tests have since been developed, including: the step-rate test (Felsenthal 1974); the aforementioned HTPF test (Cornet and Valette 1984); a hydraulic jacking test developed specifically for pressure tunnel investigations (Brekke and Ripley 1987); the cyclic hydraulic jacking test (Rutqvist and Stephansson 1996) and; though not strictly a hydraulic jacking test, the modified Lugeon test (Philippe et al. 2019).

Hydraulic jacking tests are considered highly relevant for assessing stresses in connection with unlined pressure tunnel design since they are relatively simple to execute and they simulate the effect imposed on the rock mass by the pressurized water (Doe and Korbin 1987; Benson 1989; Broch et al. 1997; Merritt 1999). Testing is commonly performed during the constructional phase of hydroelectric projects, with number and location of tests based on local conditions.

The normal testing procedure is to drill boreholes in various directions into the rock mass surrounding the tunnel, and then install a single packer at a depth where stress influence from the tunnel can be ignored, to isolate a section of borehole. This borehole section, which typically is $5-15 \mathrm{~m}$ long, is then injected by water until the water pressure $\left(P_{\text {inj }}\right)$ exceeds the in situ normal stress acting across the fracture most favourably oriented for opening, effectively providing a single measure of the magnitude of normal stress supported by the stimulated fracture, see Fig. 2. Tests are typically pressure controlled with pressure increments of $0.3-1 \mathrm{MPa}$, and with each increment held a few minutes until steadystate conditions are achieved. Each test cycle consist of a stepwise pressure increase followed by stepwise decrease with the same pressure increments. Testing in several holes and repeated cycles in each hole are commonly performed to improve the reliability of the measurements.

The interpretation of hydraulic jacking tests traditionally has been based on assumption of a distinct fracture opening or closure when $P_{\text {inj }}$ equals or just barely exceeds the normal stress acting across the fracture. This assumption is, however, not necessarily valid, since it has been found that 
fracture opening and closure are gradual, rather than distinct, which affects the interpretation of test results (Rutqvist and Stephansson 1996). Still, the pressure at the transition from a gradual to a linear pressure decline might serve as a reasonable, lower bound, normal stress estimate (Hartmaier et al. 1998).

\section{Experimental Setup}

The experiments reported in this article have been performed in a newly developed true triaxial test rig, designed specifically for performing these experiments. In the current laboratory setup, we know in advance the magnitude of normal stress acting across the tested fractures, and it is, therefore, possible to assess how well various testing procedures can predict this "true" value under various testing configurations. This, in turn, may provide input on how field-scale hydraulic jacking tests should be performed to provide a sound estimation of normal stresses across fractures, while at the same time keeping the test as simple and cost-effective as possible. To investigate this, a number of laboratory-scale hydraulic jacking experiments on cubical rock blocks subjected to true triaxial confinement have been performed. Confinement of the rock specimen has been achieved by placing the specimen inside a stiff test frame and pressurizing the specimen sides from three orthogonal directions, the magnitude in each direction individually adjustable between 0 and $20 \mathrm{MPa}$.

\subsection{Test Rig}

The test rig, shown in Fig. 3, consists of the following main units: a custom built true triaxial test frame with an integrated crane; a monitoring system for monitoring fluid pressure, fluid flow and acoustic emission (AE) signals, and a high-pressure reciprocating injection pump.

The modular test frame, made to order by Sollie Solutions AS, is made of structural steel (S355) and consists of a quadratic bottom plate on which a circular spacer element and the main steel body rests, see Fig. 4 . The main steel body has an outer diameter of $820 \mathrm{~mm}$ and the minimum material thickness is $80 \mathrm{~mm}$. On top is an 80-mm-thick lid which can be hoisted with the integrated hydraulic crane. The top lid is fixed with four $\varnothing 60 \mathrm{~mm}$ high strength $(\mathrm{S} 165 \mathrm{M})$ tension bolts running from the bottom plate through the top plate. Three $30 \mathrm{~mm}$ openings, angled $0^{\circ}, 15^{\circ}$ and $30^{\circ}$ from the vertical, run through both top lid and the upper sensor platen, enabling drilling into the specimen under confinement and used also for installation of the injection packer into a confined specimen. The rock specimen is located centrally in the loading frame, surrounded by platens of different thicknesses, including six $19 \mathrm{~mm}$ sensor platens, housing

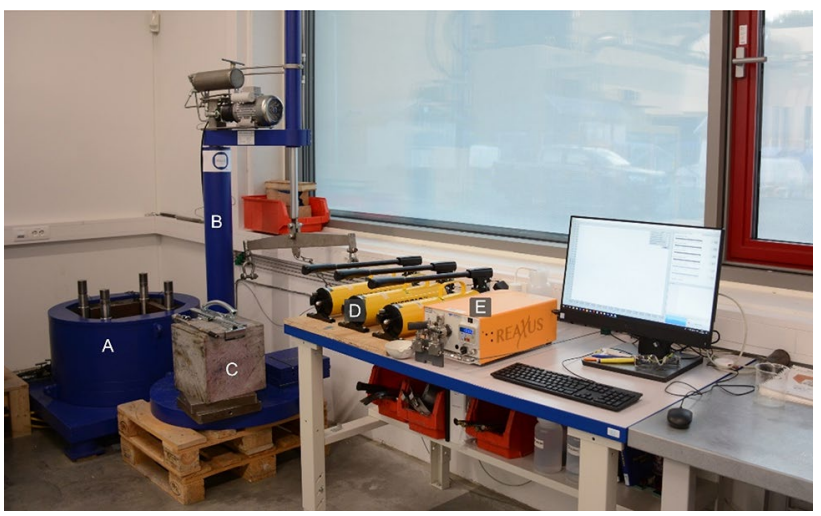

Fig. 3 Overview of the test rig. From left to right is a the test frame, b the integrated hydraulic crane, c one of the granite specimens resting on the top lid, $\mathbf{d}$ three hand pumps used for pressurizing the hydraulic pistons, e the high-pressure pump used to pressurize the test section, and the desktop computer where tests are controlled and monitored

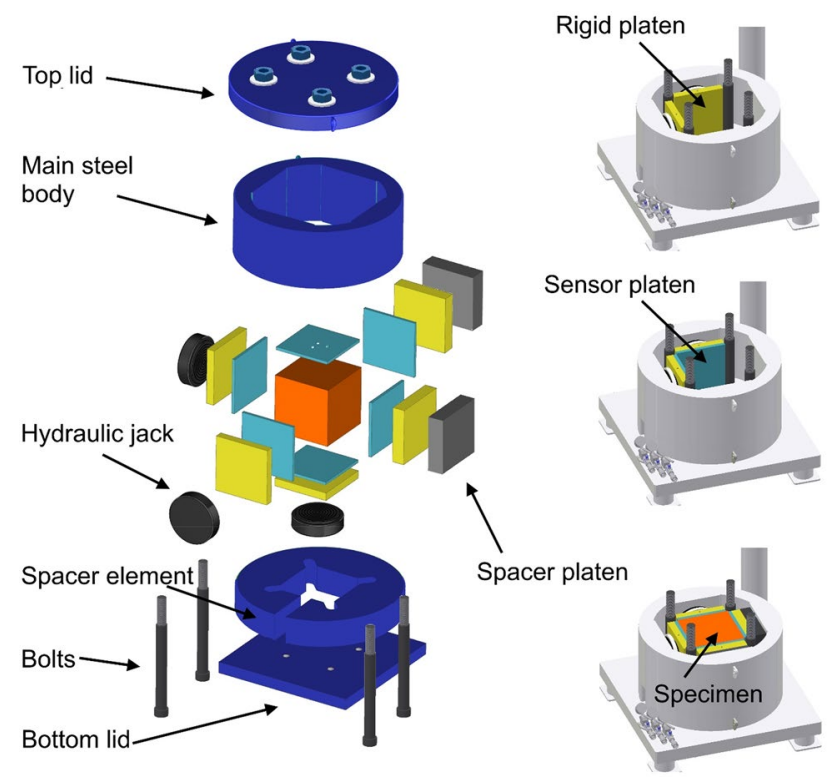

Fig. 4 Assembly drawing of the test rig to the left, and the rig at various stages of assembly to the right

acoustic emission (AE) sensors; five 40-mm-thick rigid platens, ensuring even load transfer from the cylinder to the specimen; and two $60 \mathrm{~mm}$ dummy platens, serving as rigid spacer elements, see Fig. 4. All platens are $290 \mathrm{~mm}$ wide, slightly smaller than the specimen width, to avoid contact between neighbouring platens during testing. Three hydraulic cylinders were used to load the specimen sides. Each cylinder is pressurized with a hand pump, allowing for individual control of the three stress directions according to the desired stress configuration. Since the stresses are intended to simulate a tectonic stress situation, no adjustment of stress 


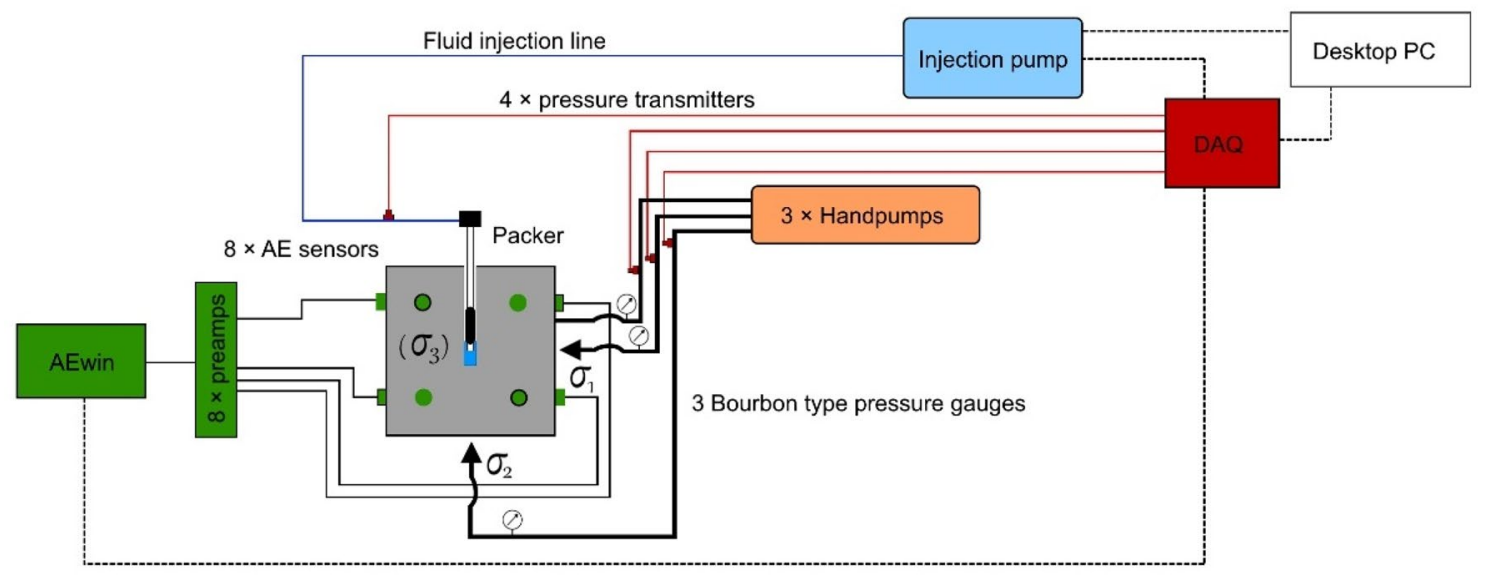

Fig. 5 Schematic overview of the monitoring system (side view). $\sigma_{3}$ in brackets indicate that it is the stress in the direction normal to the paper plane

was made during the test. The hydraulic cylinders have an integrated tilting function, where the plunger can be tilted up to $4^{\circ}$ from the loading axis, thus accommodating minor rotations between the moving and stationary parts of the cylinder to prevent uneven loading, similar to the effect of spherical seats. To enhance load transfer was the diameter of the hydraulic piston was chosen such that it would be close to that of the specimen. Similar design choices for true triaxial rigs have been described by Zhang and Fan (2014) and Shi et al. (2013).

Confining pressures $\left(P_{\text {jack }}\right)$ and injection pressures $\left(P_{\text {inj }}\right)$ were monitored by four pressure transmitters, each having a $1 \mathrm{kHz}$ sampling rate. The pressure data were displayed real-time throughout testing and data was stored for posttest analysis and processing. As a backup, the fluid pressure in the hydraulic lines could also be monitored by separate gauges, in the form of a $10 \mathrm{~Hz}$ pressure transmitter integrated with the injection pump, and three Bourdon pressure gauges for the confining pressures. A simplified overview of the monitoring system is shown in Fig. 5.

A dual piston reciprocating pump capable of providing $28 \mathrm{MPa}$ injection pressure, at a maximum flow of $100 \mathrm{ml} /$ min, was used to pressurize the borehole test section. The pump was factory configured to flow-control mode. The flow was controlled through a programme developed in LabVIEW, and was adjustable in $0.1 \mathrm{ml} / \mathrm{min}$ increments within the full flow range from 0.1 to $100 \mathrm{ml} / \mathrm{min}$. A high-pressure stainless steel fluid injection line was used to transfer water from the pump to the packer, where the water entered the test section via the packer rod. Return flow, when needed, was directed through a separate return line equipped with two autoclave needle valves marked as "A" and "B" in Fig. 6. This valve arrangement serves the dual purpose of venting the system as well as enabling flow-back over a constant choke by fixing valve "B" at a pre-determined choke and shutting the flow on and off with valve "A" (though this latter option was not been employed for the experiments described in this paper). The total water volume in the tubing and test section was approximately $44 \mathrm{ml}$, distributed between the high-pressure tubing $(10 \mathrm{ml})$, the packer rod $(14 \mathrm{ml})$ and the open-hole sections $(20 \mathrm{ml})$.
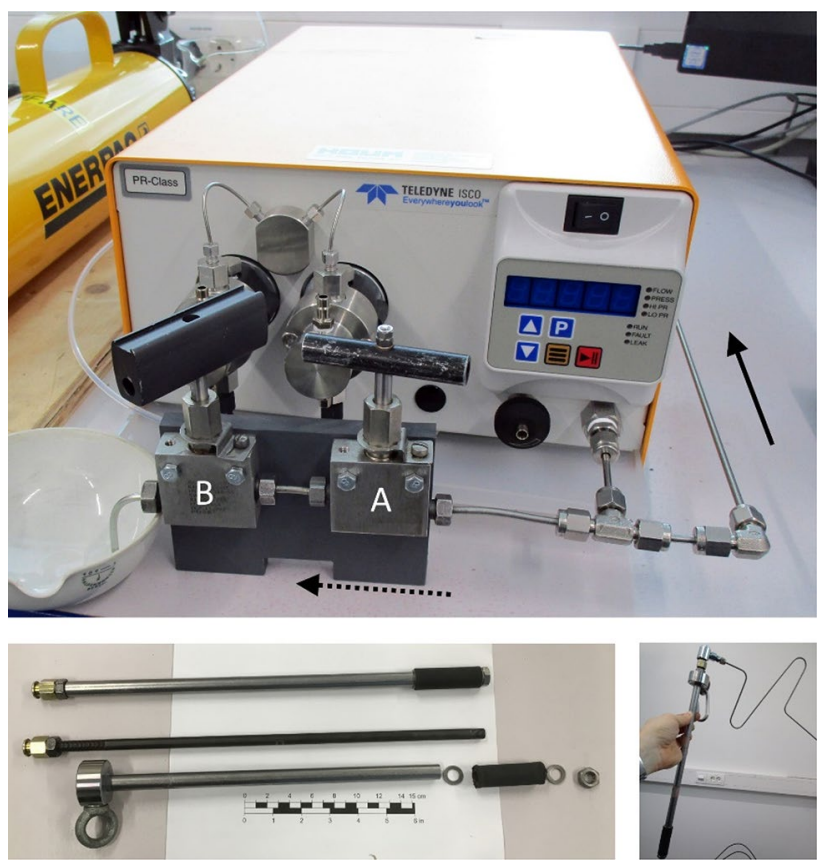

Fig. 6 Injection pump and packer assembly. Top: pump with valve configuration enabling flow-back. Unbroken arrow indicates flow direction during injection, dotted arrow shows direction during flowback and venting. The lower left picture shows the injection packer with scale indicated. Note, the in-house modification of the upper part of the packer rod, incorporating an eye bolt for secure anchoring of the packer during testing. The expansion loop in the steel pipe is shown in the lower right photo 


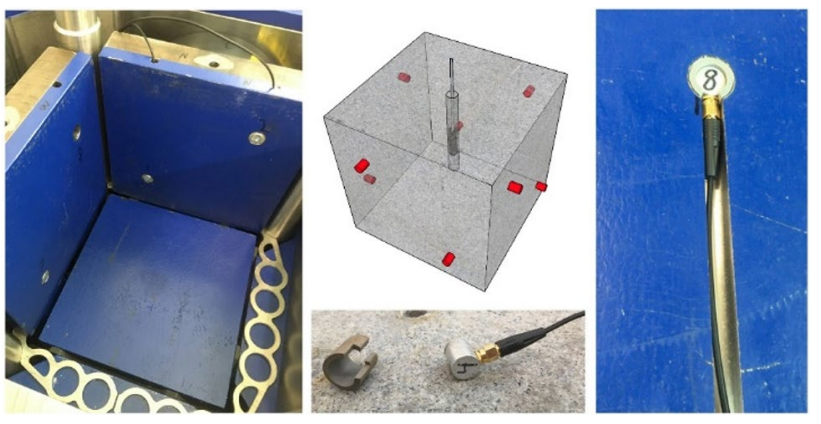

Fig. 7 AE sensor-mounting overview, showing sensor platens to the left, the AE sensor arrangement with two sensors placed in contact with each of the four sensor sides at the top middle, the loose rubber jacket used to protect the $\mathrm{AE}$ sensor from noise at the lower middle, and the sensor when mounted in the sensor platen (rear-side view) to the right

A $19 \mathrm{~mm}$ high-pressure, mechanical injection packer was used to isolate the test section during testing. This kind of packer is structurally similar to the single-use packers commonly used for both field-scale hydraulic jacking tests and rock mass grouting, and has the advantage of being easy to handle, durable and highly efficient in sealing the borehole. The injection line tubing was connected to the packer by a sliding coupling connection, enabling a fast and watertight connection. The downstream section of steel tubing was given an expansion loop to ensure better manoeuvrability of the tubing when connecting to the packer. The packer and steel pipe with the sliding connection are shown in Fig. 6.

\subsection{AE Monitoring}

AE monitoring was used as an aid in the analysis of pressure and flow data, enabling linking of AE activity with the mechanical behaviour of the stimulated fractures during hydraulic testing. The orientation of the fracture could also be mapped by $3 \mathrm{D}$ event localization, where each hypocentre represented a single point in a point cloud representing the fracture. During all tests, AE signals were monitored using eight broadband AE sensors with a $500 \mathrm{kHz}$ operating frequency. The sensors, AE-HTRX type, were connected to an AE measurement system consisting of eight 2/4/6 voltage preamplifiers and an eight-channel acoustic emission PCI card configured with AEwin software, version E5.90. The preamplifiers gain was set to $40 \mathrm{~dB}$ for all channels.

Two holes for the AE sensors, with appurtenant grooves for the AE cables, were machined in each sensor platen to protect the sensors from the cylinder load. This arrangement enabled direct contact with the specimen side without damaging the specimen, see Fig. 7. Each AE sensor is $18.7 \mathrm{~mm}$ high with $22.2 \mathrm{~mm}$ diameter. Each sensor was wrapped with a 3-mm-thick rubber jacket to minimize acoustic contact between the side of the sensor and the steel platen. In
Table 1 Typical values of some index properties of the Iddefjord granite

\begin{tabular}{ll}
\hline Property & Value \\
\hline Density $\left(\mathrm{kg} / \mathrm{m}^{3}\right)$ & 2630 \\
Poisson's ratio & 0.30 \\
Porosity $(\%)$ & $<1$ \\
Sound velocity, $V_{\mathrm{p}}(\mathrm{m} / \mathrm{s})$ & 4000 \\
Uniaxial compressive strength $(\mathrm{MPa})$ & 230 \\
Brazilian tensile strength $(\mathrm{MPa})$ & 9 \\
\hline
\end{tabular}

addition, on the passive side of each sensor, a penny-shaped piece of rubber was placed to ensure that a gentle pressure was transmitted from the rigid platen to the sensor, promoting good acoustic coupling with the specimen.

\subsection{Rock Specimens}

The specimens used in all experiments were cubes of Iddefjord granite, cut from a quarry in south-eastern Norway. The approximately $920 \mathrm{Ma}$ old granite was chosen due to its homogeneity, low permeability, and availability. The side lengths of the tested rock cubes were $300 \mathrm{~mm} \pm 0.5 \mathrm{~mm}$. Opposing sides of the cubical specimens were sawn parallel to $\pm 0.4^{\circ}$, as measured by a precision protractor. Main index properties of the Iddefjord granite are given in Table 1.

\subsection{Test Preparation}

Each rock specimen was visually inspected for damage before testing, and the P-wave sound velocity $\left(V_{\mathrm{P}}\right)$ measured. A vertical, 180-mm-deep borehole was drilled with a hand-held percussion drill from the top centre of the specimen through the specimen centroid such that a $60 \mathrm{~mm}$ openhole test section could be established in the middle of the sample, as shown in Fig. 8. After drilling, the borehole was flushed thoroughly with water until clear return water could be observed. The selected $20 \mathrm{~mm}$ hole diameter was considered an optimal dimension as it is large enough to be comparable to field-scale operations (Haimson and Zhao 1991), but at the same time small enough to avoid stress perturbation away from the borehole.

To facilitate the hydraulic jacking tests, a new fracture had first to be made in the initially intact rock specimens. This was done by confining the specimen inside the rig and hydraulically fracturing it, using the same equipment used for later hydraulic jacking tests. To promote the development of a vertical fracture a stress configuration with $\sigma_{\mathrm{H}}>\sigma_{\mathrm{v}}>\sigma_{\mathrm{h}}$ was chosen. Despite omitting, any pre-slotting of the borehole to control the fracture direction the fractures developed fairly planer and close to vertical, in a classic bi-wing (i.e. to both sides of the borehole) manner. 


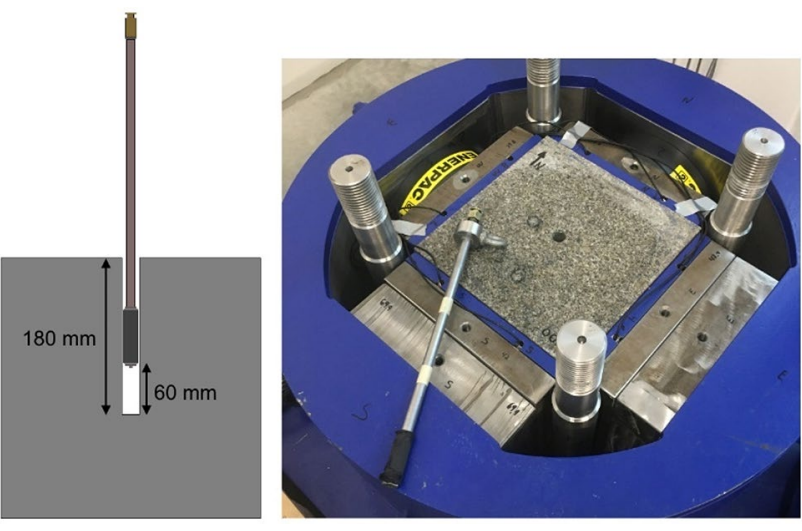

Fig. 8 Overview of packer and packer placement, with the location of the packer elements inside the specimen shown to the left and the packer resting on top of the mounted specimen to the right

Before lowering the specimen inside the test frame, a thin layer of acoustic couplant was applied to the active side of the AE sensors, i.e. the surface in contact with the specimen. A paving slab lifter was used to clamp the specimen as it was lowered into the test frame using the integrated crane. Once the specimen had been placed inside the test frame, and the four sensor platens placed in contact with the specimen, the remaining platens could be installed, ensuring both a snug fit and that the specimen was maintained centrally in the test frame, as shown in Fig. 8. An initial check of the acoustic coupling was then made by first confining the specimen to $1 \mathrm{MPa}$ in both horizontal directions, and then performing a pencil-lead test to ensure satisfactory acoustic contact between specimen and sensor.

For all tests, the true triaxial stress field, with $\sigma_{\mathrm{H}}=7 \mathrm{MPa}$, $\sigma_{\mathrm{h}}=3 \mathrm{MPa}$ and $\sigma_{\mathrm{v}}=4 \mathrm{MPa}$, was kept constant throughout the test. The chosen stress magnitudes were considered representative for stress conditions at typical depths of Norwegian hydroelectric projects where, due to the predominantly compressional tectonic regime in Norway, the maximum horizontal stress commonly exceeds the magnitude of the vertical stress. The stress directions were set to promote hydraulic jacking of the existing hydraulic fracture, and not creating new fractures, i.e. by ensuring that the direction of minimum horizontal stress was closest to normal to the fracture, and that the maximal horizontal stress was closest to parallel to the fracture. The stress directions, stress magnitude and fracture orientation for all specimens are shown in Fig. 9.

After confinement of the specimen, the packer could be installed and tightened, thus representing the actual field condition. The packer rod was topped off with water and the injection line thoroughly flushed prior to connecting the high-pressure injection line to the packer, to avoid trapped air in the system. Low-pressure injection into the test section was performed prior to each test to check for any leaks, causing the fracture to be wetted prior to testing. The specimen
Fig. 9 Stress field and fracture orientation for the tested specimens, topside views

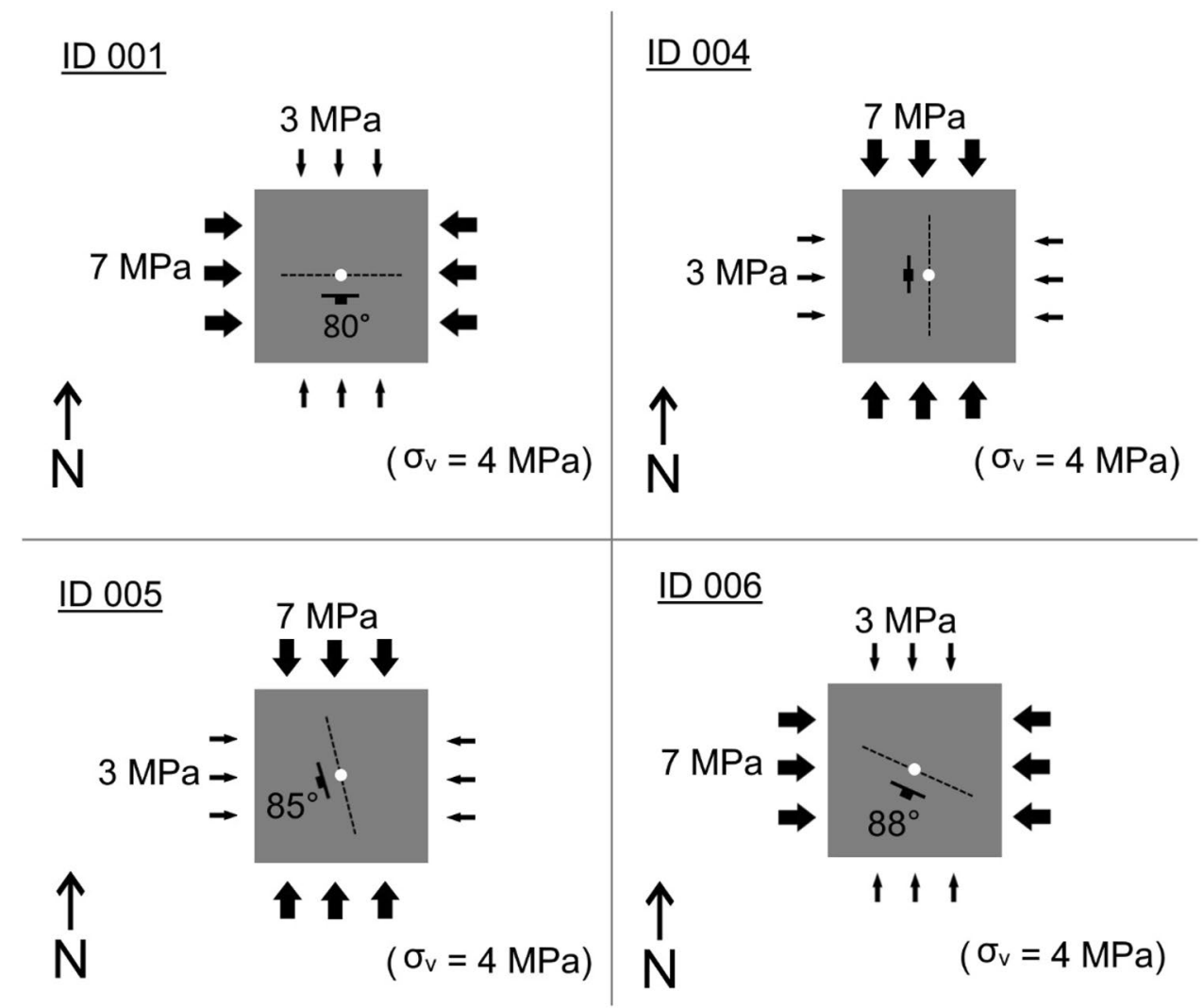


Fig. 10 Overview of test types, RSRT to the left, Type B to the right

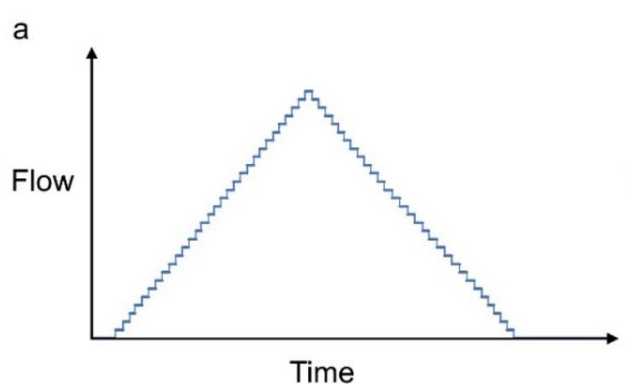

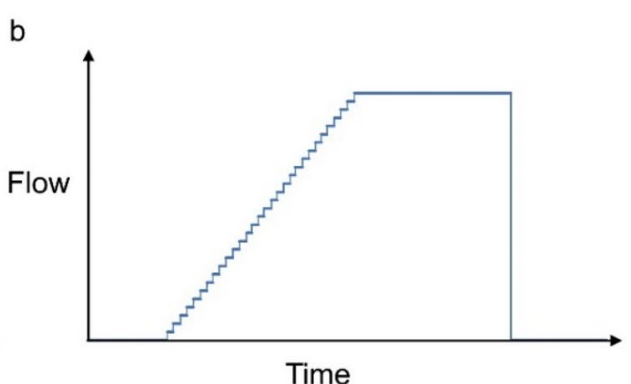

itself was unsaturated prior to testing. Ordinary tap water at ambient temperatures was used in all tests. Any water reaching the sample boundaries during testing is effectively drained along the sensor platen-specimen interface before being drained out of the test rig. The packer rod was anchored to the crane yoke prior to testing, a final safety measure to avoid sudden release and ejection of the packer during testing.

\section{Experimental Results}

\subsection{Test Procedure}

Two types of hydraulic jacking experiments have been conducted as part of this study. The first is a rapid variant of the step-rate test, hereafter termed the rapid step-rate test (RSRT), where water is injected in a series of pre-determined flow steps, and the corresponding response in injection pressure, $P_{\text {inj }}$ is registered. The test starts with forward-step flow increments until hydraulic jacking occurs, interpreted in the test as a distinct deviation from the initial linear stage in the pressure-time plot. After hydraulic jacking, the test continues with backward-step flow reduction down to zero flow, similar to that of the Fracture reopening-option 3 of the HTPF method (Haimson and Cornet 2003).

The stepwise flow change, and relatively small flow increment of each step, ensures that the pressure in the test interval can be raised steadily, even when the initial permeability of the test section is unknown.

For the second test type, termed Type B, the first part of the procedure is basically identical with the RSRT, using the same ascending flow increments. In the second half of the test follows a brief period of constant flow before the pump is stopped without venting the injection line, similar to that of the Fracture reopening-option 2 of the HTPF method (Haimson and Cornet 2003). It should be noted that, due to the experimental setup, no traditional shut-interpretation to assess the fracture normal stress is intended, since it is believed that the leaky periphery (fracture extending to specimen edges) would cause gradual fracture closure and thus indistinct shut-in pressure interpretation (Rutqvist and
Stephansson 1996). The shut-in phase is instead performed to investigate the acoustic emission (AE) response to fracture closure. The idealized, flow/time curves for the two test types are shown in Fig. 10.

An important feature of both test procedures is that the flow change for each step, and the duration of which each flow step is maintained, is kept constant throughout the test. For the experiments presented in this paper, each flow step is fixed at $1 \mathrm{ml} / \mathrm{min}$, and the duration of each flow step is $1 \mathrm{~s}$, giving a flow rate change of $1 \mathrm{ml} / \mathrm{min} / \mathrm{s}$. Consecutive tests on the same specimen were made without removing the specimen from the test rig between tests. The RSRT was performed first, and, after waiting a minimum of $0.5 \mathrm{~h}$, Test $\mathrm{B}$ was performed.

\subsection{Fracture Orientation}

To enable calculation of the normal stress across the different fractures, the orientation of each fracture had to be known. This was done by investigating the AE hypocentre location from 3D AE data and, where applicable, by direct measurements of visible fracture trace on the specimen sides. Though the fracture itself rarely was visible to the naked eye, it could be traced on the specimen sides either by post-test injection of water with methylene blue, a watersoluble dye, or from the colour contrast from the wetted fracture against the otherwise dry specimen. This combined fracture mapping provided an efficient and non-destructive means of identifying the fracture orientation and shape. To illustrate the ability of the AE system to locate the fracture, an $\mathrm{AE}$ hypocentre plot has been draped on a photo of the actual specimen immediately after removing the sample from the test rig after testing, see Fig. 11.

The fracture surfaces were not perfectly planar, and one single value for the orientation had to be chosen for the normal stress calculation. This orientation is termed the Representative Dip/dip-direction. The combined uncertainty due to variation in fracture orientation (the fact that the fracture is not entirely planar), and due to inaccuracy of orientation measurement, is estimated to be $\max \pm 5^{\circ}$ for dip-direction and $\pm 2^{\circ}$ for dip, representing a max. error of about $0.28 \mathrm{MPa}$ in the normal stress calculation. The dip- and dip-direction 


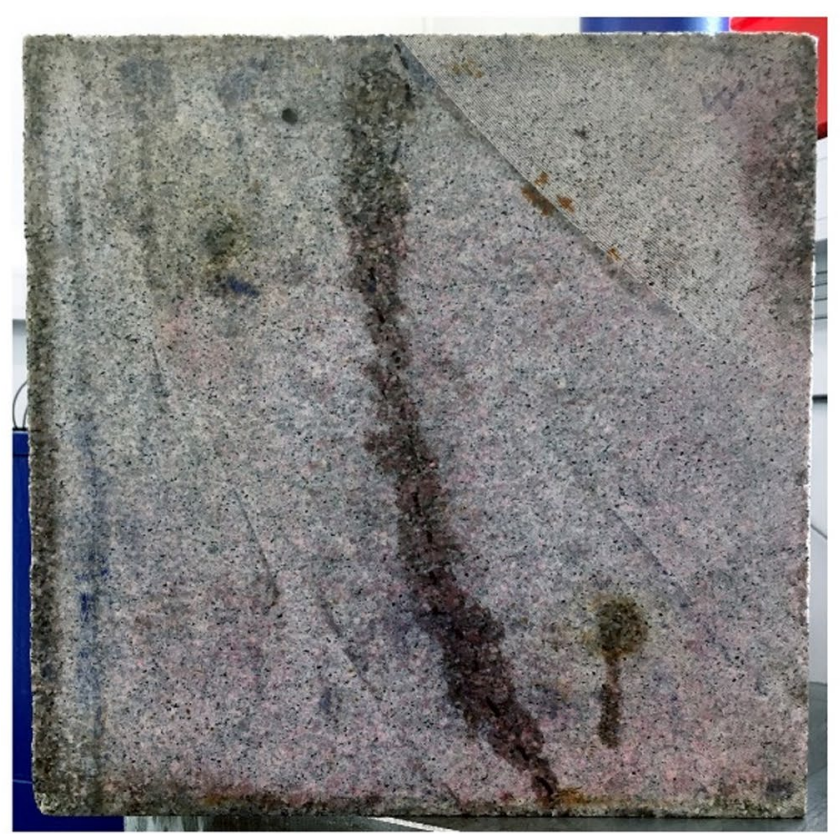

Fig. 11 Correlation between AE hypocentre locations and hydraulic fracture. Granite specimen (ID 001) after hydraulic stimulation shown to the left, with the wetted fracture trace shown as a dark line running vertically from the top centre, curving slightly to the right.

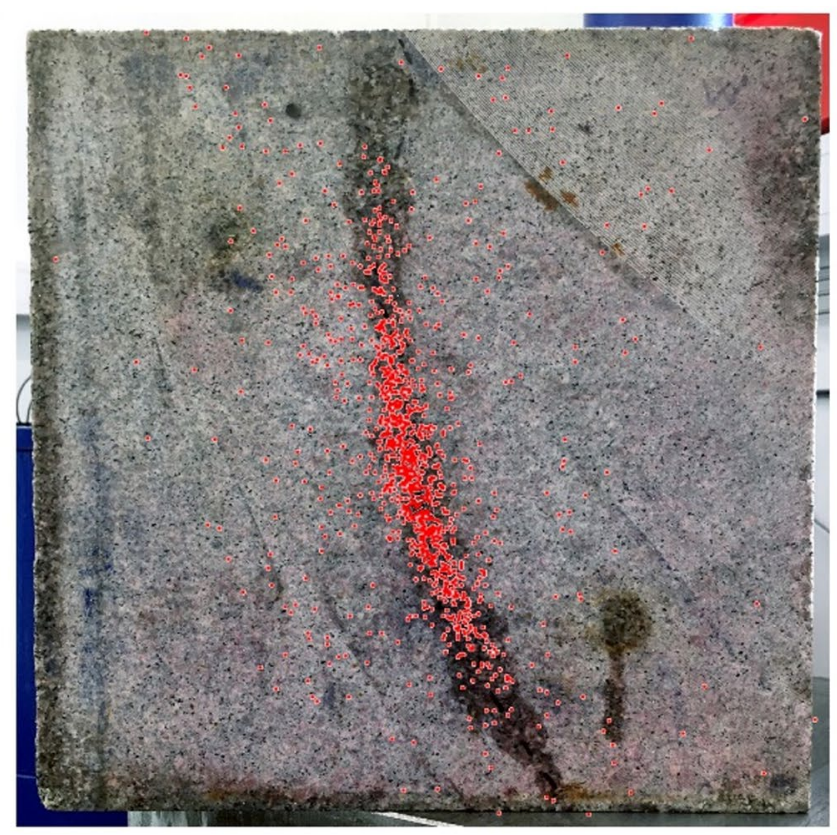

To the right is a compiled view of the same specimen photo, draped with the AE hypocentre locations (red dots) originating from hydraulic jacking test. The two dark dots visible in the lower right and upper left are caused by residue from the acoustic couplant

Table 2 Fracture orientation for the tested specimens

\begin{tabular}{lll}
\hline Specimen ID & $\begin{array}{l}\text { Representative } \\
\text { dip/dip-direc- } \\
\text { tion }\end{array}$ & Comment \\
\hline 001 & $80 / 180$ & $\begin{array}{l}\text { Bi-winged fracture. The fracture is fairly planar, but slightly curved towards south in the lower parts of the } \\
\text { fracture } \\
\text { Bi-winged vertical fracture. The northern branch in planar, striking exactly N-S and the southern branch devi- } \\
\text { ating slightly towards the S-SE } \\
\text { Bi-winged planar fracture developed mainly in the specimen's upper half } \\
\text { Bi-winged and fairly planer fracture, but with the south-eastern branch deviating slightly from that of the north- } \\
\text { western }\end{array}$ \\
005 & $90 / 090$ &
\end{tabular}

for each fracture, relative to the local north (see Fig. 9), is provided in Table 2, together with a brief description of the fracture.

\subsection{Rapid Step-Rate Tests}

\subsubsection{Pressure-Time Plots}

Four tests using the RSRT procedure, tests 001-A, 004-A, 005-A and 006-A, have been performed as part of this study. The injection pressures and flow rates are plotted as function of time in Fig. 12. For all tests, an initial linear trend can be observed in the ascending pressure-time curve, representing the combined effect of minor fluid leakage to the specimen and elastic deformation of the test system, the latter caused primarily by compression of the water and the rubber packer. The observed variation of initial pressure development, as seen for the different specimens, reflect the unique hydraulic properties of the stimulated fractures, of which the residual aperture is believed to be the predominant. The point on the ascending pressure-time curve where the initial linear trend deviates from linearity, indicate increased fluid leak-off and marks the onset of hydraulic jacking. Opposite, in the descending pressure-time curve, the start of a linear pressure decay indicates fracture closure and corresponding reduced fluid leak-off.

Starting with test 001-A in Fig. 12, a linear pressure increase can be observed until deviation at $P_{\text {inj }}=3.8 \mathrm{MPa}$, suggesting leak-off. From the start of the descending flow steps, at $t=83 \mathrm{~s}$, a non-linear pressure decline can be 

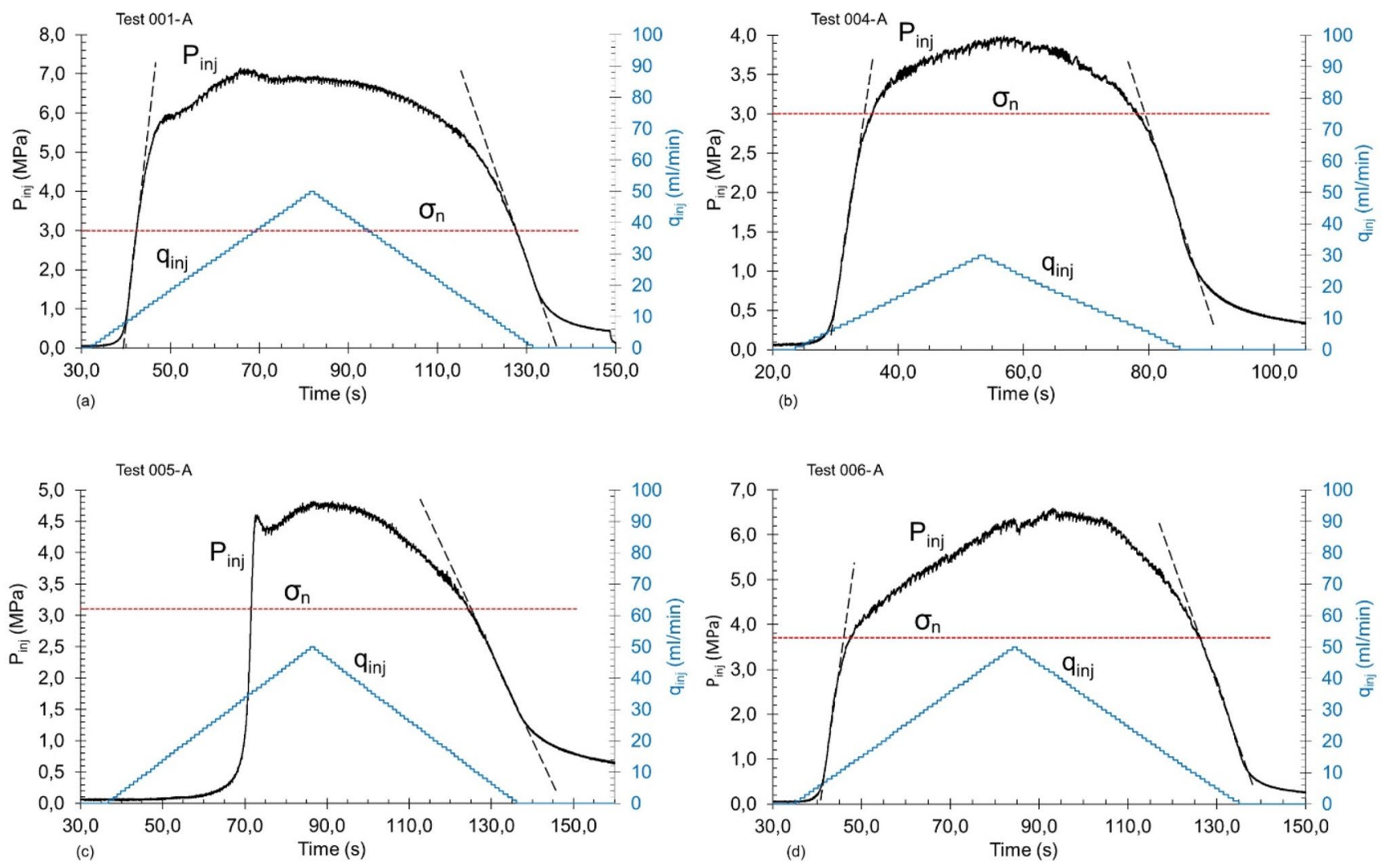

Fig. 12 Injection pressure variation as a function of time and flowrate for tests 001-A, 004-A, 005-A and 006-A. The horizontal, red line indicates the magnitude of the calculated normal stress acting across

each respective fracture. Where applicable, a dashed line has been drawn to highlight the deviation from the linear trend in the pressuretime curve

observed until $P_{\text {inj }}=3.2 \mathrm{MPa}$, followed by a linear pressure decay, indicating fracture closure. A similar pattern can be observed for test 004-A, with deviation from the linear trend starting at $P_{\text {inj }}=2.6 \mathrm{MPa}$, suggesting fracture opening. Then, following a gradual pressure decay after reversal of flow steps, a linear pressure decay can be observed at $P_{\text {inj }}=2.6 \mathrm{MPa}$, suggesting closure. The ascending pressure curve of Test 005-A differs from 001-A and 004-A by, following an initial linear pressure increase, a distinct breakdown at $P_{\text {inj }}=4.6$, suggesting minimal fluid leak-off and a rather sudden fracture opening. After reversal of flow steps, a gradual pressure decay, similar to that of the preceding two tests, can be observed until $P_{\text {inj }}=3 \mathrm{MPa}$, from where a linear pressure decay takes place-suggesting fracture closure. For Test 006-A, deviation from linearity of the ascending pressure-time curve occurs at $P_{\text {inj }}=3.2 \mathrm{MPa}$. As for the previous three tests, a gradual pressure decline is then followed by a linear decay, in this case starting at $P_{\text {inj }}=3.8 \mathrm{MPa}$. For some of the tests, a pressure increase can be observed even after flow step reversal, causing the local $P_{\text {inj }}$ peak to occur after the $q_{\text {inj }}$ peak. This only reflects that, even though the flow rate is being reduced, the volume of fluid being injected still exceeds that which is leaking out.

From these observations, it seems clear that the pressure at which fracture closure occurs is in close agreement with the normal stress. The pressure observed at fracture opening, however, does not show similar agreement with fracture normal stresses, with apparent fracture opening occurring at pressures both higher and lower than the fracture normal stress. A summary of the interpreted opening and closure pressures for the four tests is given in Table 3.

During testing, can a small, but distinct, increase of the confining pressure $\left(P_{\text {jack }}\right)$, in the direction normal to the fracture, be observed, see Fig. 13. The onset of this pressure increase occurs prior to any clear signs of hydraulic jacking in the $P_{\text {inj }}-t$ plot, and well below the fracture normal stress. This clearly indicate that some fluid enters the fracture prior to hydraulic jacking, causing minor fracture opening and a corresponding push-back on the confining pressure. This is believed to be related to the mechanism discussed in Sect. 2.3, where it is shown how minute fracture opening at fluid pressures lower than the fracture normal stress, can be one of the reasons why reopening (and closing) of a pressurized fracture is believed to be gradual, rather than distinct, causing some ambiguity in the interpretation of fracture 
Table 3 Summary of interpreted opening and closing pressures for the step-rate tests, compared to the normal stress on the stimulated fractures

\begin{tabular}{lllllll}
\hline Test ID & Pressure-time plots & & $q P$-plots & $\begin{array}{l}\text { Calculated normal stress } \\
\text { across fracture (MPa) }\end{array}$ \\
\cline { 2 - 3 } & $P_{\text {inj (opening) }}(\mathrm{MPa})$ & $\begin{array}{l}P_{\text {inj (closure) }} \\
(\mathrm{MPa})\end{array}$ & $P_{\text {inj (opening) }}(\mathrm{MPa})$ & $\begin{array}{l}P_{\text {inj (closure) }} \\
(\mathrm{MPa})\end{array}$ & \\
\hline 001-A & 3.8 & 3.2 & 3.7 & 3.2 & 3.0 \\
$004-\mathrm{A}$ & 2.6 & 2.6 & 2.4 & 2.6 & 3.0 \\
005-A & N/A* & 3.0 & & N/A* & 3.0 & 3.1 \\
006-A & 3.2 & 3.8 & 2.9 & 3.7 & 3.7 \\
\hline
\end{tabular}

*Instantaneous pressure drop

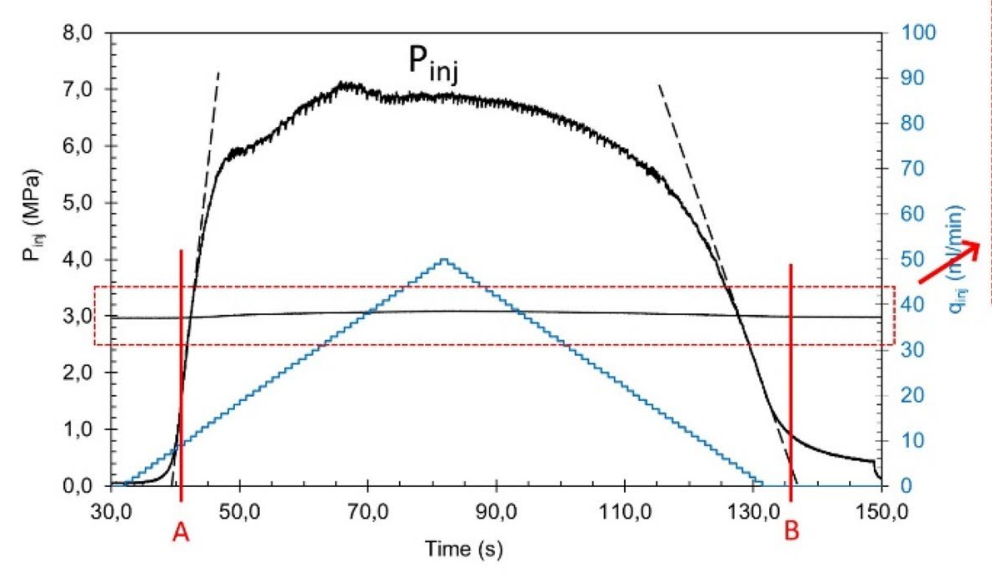

Fig. 13 Two plots of pressure and flow versus time from the same test (001-A), with the original pressure scale to the left, and a detailed view to the right, the latter highlighting the confining pressure. The

opening and closure in hydraulic jacking tests (Rutqvist and Stephansson 1996).

A similar, but much smaller, pressure response can be observed in all three confining stress directions when injecting unfractured specimens, indicating that there is some minute outward expansion of the specimen caused by the load from the pressurized water acting on the borehole walls, and to a lesser extent, from any water penetrating into microcracks in the specimen imposing an additional outward pressure (Evans et al. 1988).

\subsubsection{Flow Versus Pressure (qP-Plots)}

Hydraulic jacking test data, initially presented as real-time plots of pressure and flow vs. time in Fig. 12, are frequently presented in flow vs. pressure ( $q P$-plots), as was schematically presented in Fig. 2. We have adopted a similar way of assessing the test data in $q P$-plots as proposed by Hartmaier et al. (1998), where the transition from linear time of onset of the elevated confining pressure is highlighted with the red line marked as "A", and the time at which it ceases indicated with the red line marked "B"

to non-linear trend in the $q P$-plot is interpreted as onset of fracture dilation (jacking). However, instead of looking at the fracture-opening stage only, we use the same approach also for the fracture closure stage, interpreting the pressure at the transition from a non-linear to a linear trend in the $q P$-plot as fracture closure pressure. In Fig. 14, the corresponding graphs are presented for the four tests.

As can be seen, the interpreted fracture closure pressures in Fig. 14 are in close agreement with the interpretation made from the pressure-time plots in Fig. 12, and with the actual normal stress magnitudes. The interpreted fracture-opening pressures, however, both over- and underestimates the respective actual normal stresses. A summary of the interpreted opening and closure pressures found from the $q P$-plots is given in Table 3.

\subsubsection{Pressure-Time Plots with Acoustic Emission (AE) Rate}

For further assessment of the hydromechanical response of the fractures to the step-rate tests (shown in Fig. 12), 

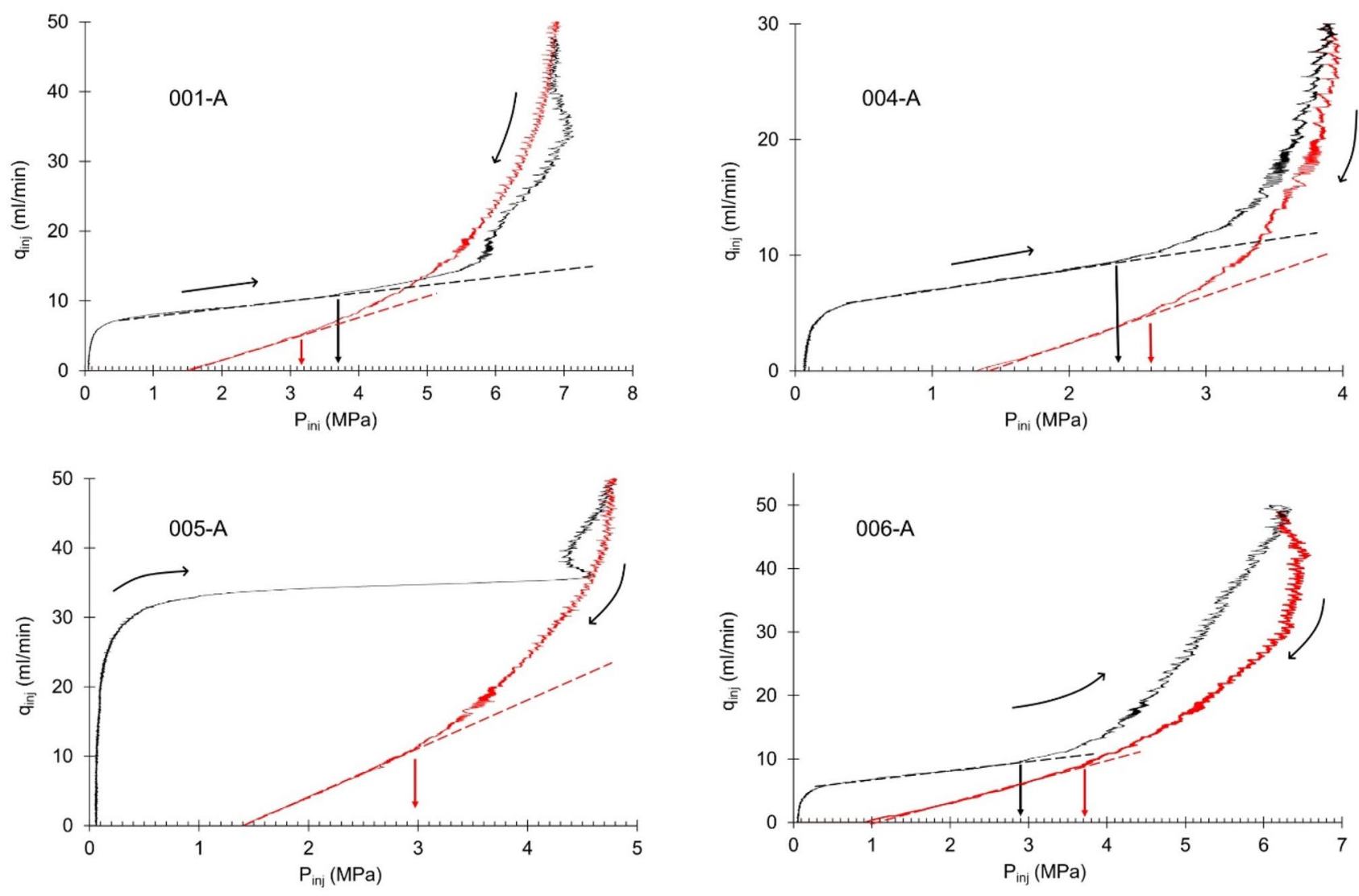

Fig. 14 Injection pressure versus flowrate for tests 001-A, 004$\mathrm{A}, 005-\mathrm{A}$ and 006-A (running average). The pressures at which the curves deviate from the linear trend (dotted line) are indicated with

a vertical arrow. The graph is given two colours to differentiate the increasing flow steps (black) and the decreasing flow steps (red)

and to investigate potential correlation between AE activity and fracture opening or closure, AE event rates have been plotted together with the step-rate test results. The resulting combined graphs are shown in Fig. 15.

As indicated by Fig. 15, certain correlations exists between the fracture behaviour and the Acoustic Emission event rate. Particularly worth mentioning are: (1) there is little or no AE activity prior to leak-off, indicating that the gradual fracture opening occurs at pressures well below the fracture normal stress, is aseismic, or generating too weak AE signals to be detected; (2) fracture reopening can generate a distinct $\mathrm{AE}$ response, with onset coinciding fairly well with the point of leak-off, and finally; (3) a distinct burst of AE activity is associated with fracture closure.

\subsection{Type B Hydraulic Jacking Test}

A total of four tests based on the Type B test procedure have been performed. Injection pressures, flow rates and $\mathrm{AE}$ event rates from these tests are plotted as functions of

time in Fig. 16. The event rate activity during the first half of each test evidently is lower than what observed for the RSRT (cf. Fig. 15), even though the initial flow stage for each test type is identical. The reason for this difference in AE behaviour may be associated with the gradual reduction of acoustic contact, caused by partial removal of the watersoluble acoustic couplant, and possibly also with changes in how well the two surfaces fit together, i.e. the fracture surface matedness. Despite this, a strong correlation between fracture closure during the shut-in period and AE activity was observed for all tests, as shown by Fig. 16.

Starting with test 001-B in Fig. 16, an initial linear pressure increase can be observed until $P_{\text {inj }}=3.6 \mathrm{MPa}$, from where deviation from linearity indicates leak-off. Full hydraulic jacking can be seen from about $t=27 \mathrm{~s}$. No distinct $\mathrm{AE}$ response is observed prior to shut-in, but a very distinct AE response can be seen after shut-in when the fracture starts to close at $t=55.7 \mathrm{~s}$, when $P_{\text {inj }}=4.5 \mathrm{MPa}$. An AE activity peak can then be seen at $t=57 \mathrm{~s}$, when $P_{\text {inj }}=3.8 \mathrm{MPa}$. The AE event rate then gradually fades out as the pressure drops further and the fracture closes. For 

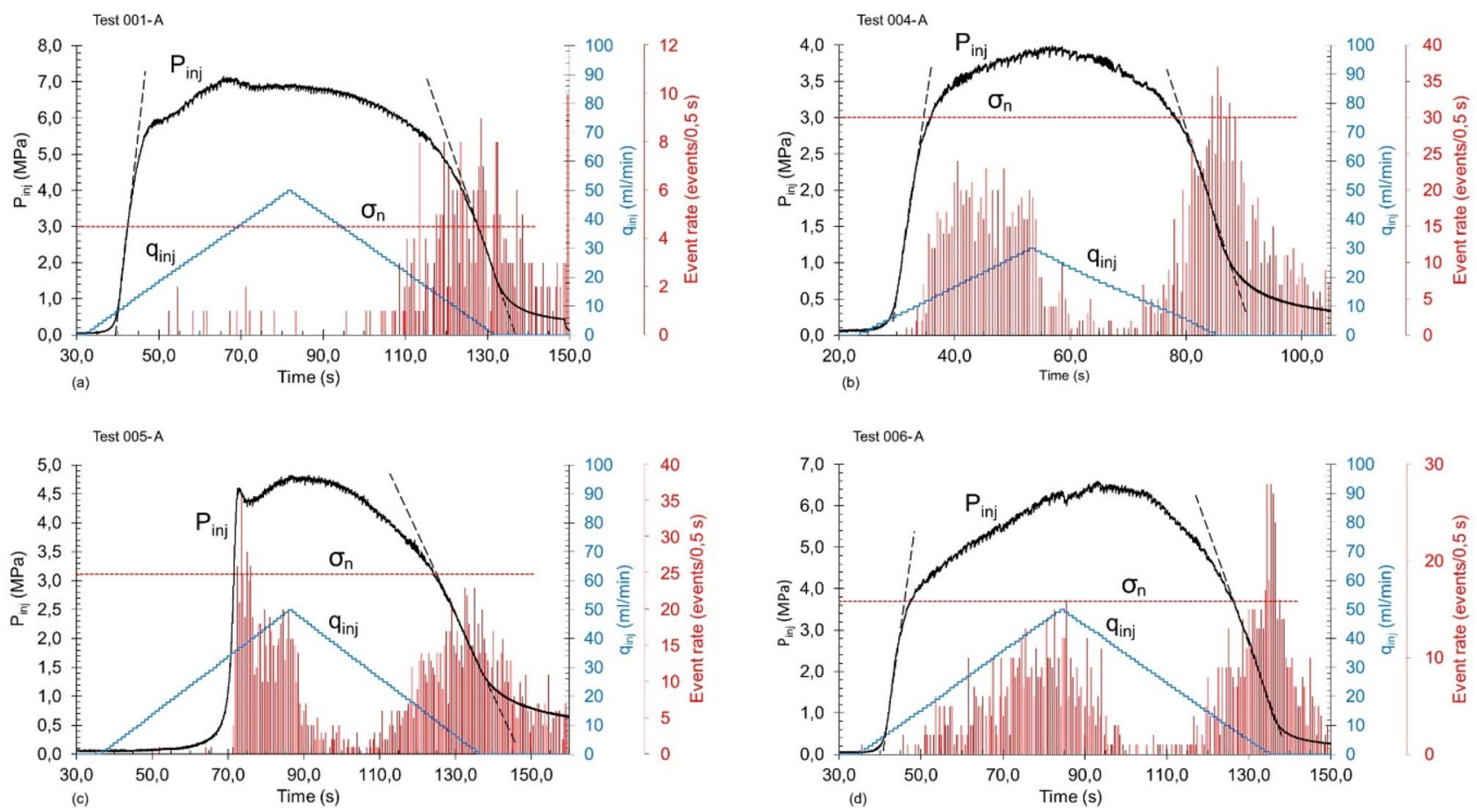

Fig. 15 Injection pressure variations as function of time, flowrates and $\mathrm{AE}$ event rates for tests 001-A, 004-A, 005-A and 006-A. The horizontal red lines indicate the magnitude of the calculated normal

stress acting across each respective fracture. Where applicable, a dashed line has been drawn to indicate the point of deviation from the straight line in the pressure-time curve
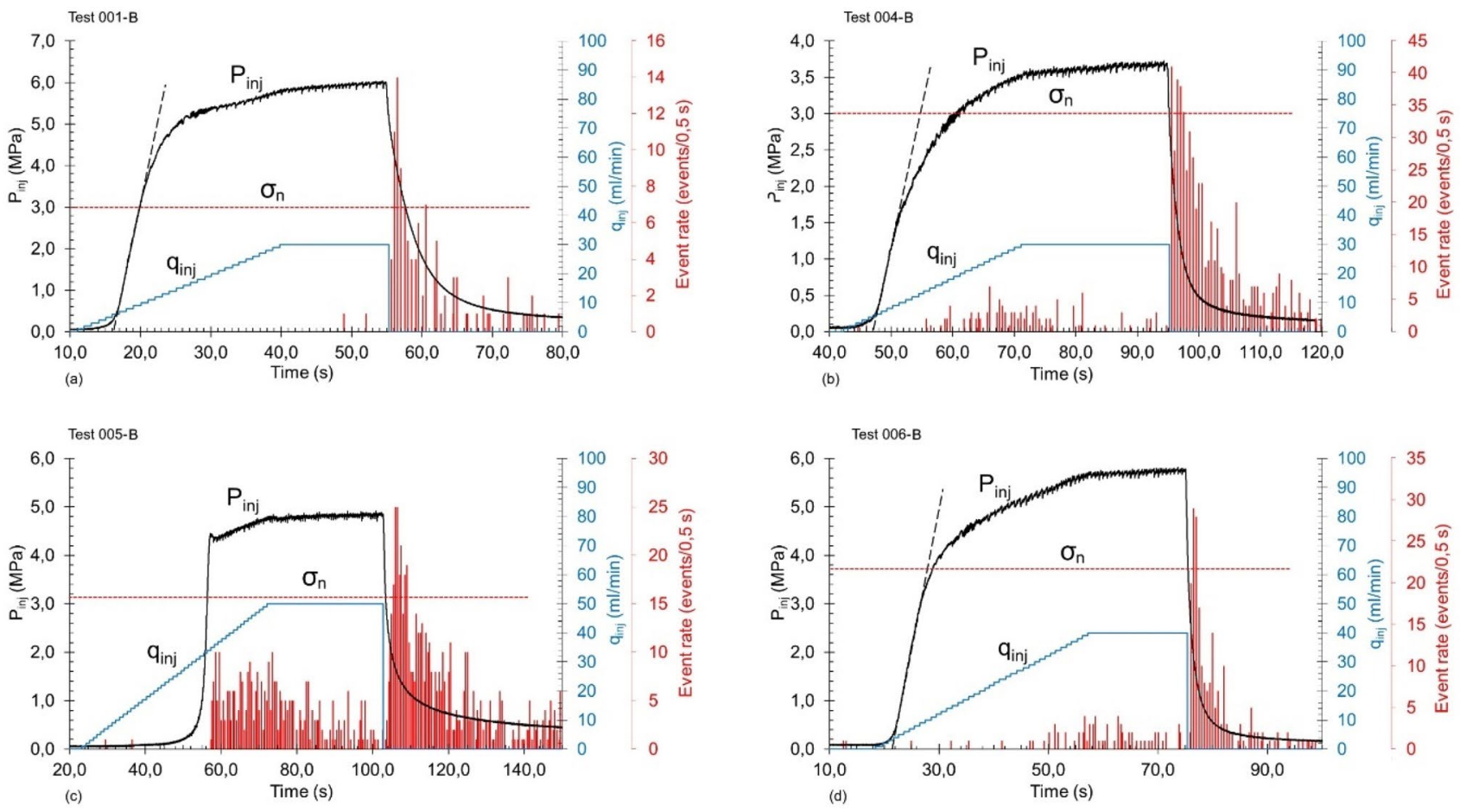

Fig. 16 Injection pressure variations as a function of time, flowrates and $\mathrm{AE}$ event rates for tests 001-B, 004-B, 005-B and 006-B. The horizontal red, dotted line indicates the magnitude of the calculated

normal stress acting across each respective fracture. Where applicable, a dashed black line has been drawn to highlight the deviation from the linear trend in the pressure-time curve 
Table 4 Summary of $P_{\text {inj }}{ }^{-}$ results for fracture opening, $\mathrm{AE}$ activity onset and AE activity peak

\begin{tabular}{lllll}
\hline Test ID & $P_{\text {inj (opening) }}(\mathrm{MPa})$ & $P_{\text {inj (AE onset) }}(\mathrm{MPa})$ & $P_{\text {inj (AE peak) }}(\mathrm{MPa})$ & $\begin{array}{l}\text { Calculated normal } \\
\text { stress across fracture }\end{array}$ \\
\hline $001-\mathrm{B}$ & 3.6 & 4.5 & 3 & 3.0 \\
$004-\mathrm{B}$ & 1.6 & 2.4 & 2.4 & 3.0 \\
$005-\mathrm{B}$ & N/A* & 2.4 & 1.7 & 3.1 \\
$006-\mathrm{B}$ & 3.4 & 2.9 & 2.0 & 3.7 \\
\hline
\end{tabular}

Calculated normal stresses are shown for comparison

*Instantaneous pressure drop test 004-B a gradual deviation from the initially linear pressure-time curve can be seen from $P_{\text {inj }}=1.6 \mathrm{MPa}$, but with no corresponding AE activity. Full hydraulic jacking can be seen from about $t=63 \mathrm{~s}$, when $P_{\text {inj }}=3.1 \mathrm{MPa}$. Immediately following shut-in a distinct $\mathrm{AE}$ response be observed at $t=95.5 \mathrm{~s}$, also marking the event rate peak occurring at $P_{\text {inj }}=2.4 \mathrm{MPa}$. The AE event rate then gradually fades out as the pressure drops further and the fracture closes. For test 005-B a distinct breakdown, occurring at $P_{\text {inj }}=4.4 \mathrm{MPa}$ can be observed after an initial linear pressure increase. A clear AE response to the breakdown can be seen with a sudden onset of AE activity. Some AE activity persists all the way to the shut-in phase, but a distinct increase in AE event rate can be observed after shut-in, the onset of which occurring at $t=104 \mathrm{~s}$ and $P_{\text {inj }}=2.4 \mathrm{MPa}$. The AE activity peak occurs at $t=106 \mathrm{~s}$, when $P_{\text {inj }}=1.7 \mathrm{MPa}$. In test 006-B a gradual deviation from the linear pressure-time curve can be seen when $P_{\text {inj }}=3.4 \mathrm{MPa}$, but with no AE activity. Full hydraulic jacking can be seen from about $t=37 \mathrm{~s}$, when $P_{\text {inj }}=4.7 \mathrm{MPa}$. Immediately following shut-in a distinct AE response can be observed from $t=76 \mathrm{~s}$ when $P_{\text {inj }}=2.9 \mathrm{MPa}$. Immediately afterwards follows the $\mathrm{AE}$ event rate peak at $t=76.5$ and $P_{\text {inj }}=2 \mathrm{MPa}$, before the AE activity gradually fades out when the fracture closes. A summary of the pressure observed at the fracture opening, AE activity onset and AE activity peak for Type B tests is presented in Table 4 .

From the above observations, it can be inferred that fracture closure is associated with a distinct $\mathrm{AE}$ response, but that $\mathrm{AE}$ data alone cannot be used to pinpoint the magnitude of normal stress, since the distinct AE response seems to appear when the fluid pressure is below the normal stress.

\section{Discussion}

\subsection{Assessment of Fracture Normal Stress}

The hydraulic jacking experiments presented in this paper are aimed at investigating the ability of a simplified hydraulic jacking test to assess fracture normal stresses in an effort to facilitate more frequent stress measurements for the final design of unlined pressure tunnels. The results from the laboratory-scale hydraulic jacking experiments performed as part of this study, have indicated that the magnitude of normal stresses acting across fractures in rock can be measured efficiently, and to a reasonable level of accuracy, by the rapid step-rate test. The RSRT procedure is similar to ordinary step-rate tests but differ by the relatively small flow increments combined with the short and fixed duration of each step, enabling rapid and semi-automated testing. This represents a major benefit for field-scale operations since the time for testing can be reduced to minutes for individual tests rather than hours as sometimes can be seen in field tests. ${ }^{1}$ The semi-automated testing procedure can further reduce operator bias and make testing more efficient since the fixed steps easily can be programmed in a computer-controlled pump. Therefore, it is believed that the RSRT can serve as one way to approach to the ideal of measuring stress regularly along the pressure tunnel rather than at a few locations only, following up the idea outlined in Ødegaard and Nilsen (2018). The short duration of each flow step does not guarantee steady-state conditions during the RSRT, but this does not invalidate the test approach since step-rate tests can be performed without reaching stabilized pressures at each step, provided that equal step-durations are used throughout the test, as discussed by several authors, e.g. (Nolte 1982; Singh et al. 1987; Economides and Nolte 2000; Lizak et al. 2006; Smith and Montgomery 2014).

The experimental results suggests that the most accurate estimate of fracture normal stresses is made by assessing data from the backward-step phase, i.e. the fracture closure phase. These findings are in qualitative agreement with those presented by Rutqvist and Stephansson (1996), who found that reopening pressures were influenced by gradual opening of the fractures-and that interpretation of fracture normal stresses from hydraulic jacking tests should be made from the fracture closure stages to avoid effects of non-linear fracture stiffness.

An additional argument for assessing normal stress from the fracture closure stages is the fact that fractures can dilate

\footnotetext{
${ }^{1}$ Unpublished test results from hydraulic jacking tests performed at the Verma HPP, Injeksjonsteknikk (2017).
} 
at hydraulic pressures lower than the fracture normal stress due to shear movement (Rancourt 2010). Even though this can affect the interpretation of the fracture-opening pressure, the shear stress will be released upon fracture opening, and a stiffness contrast can still be observed during the fracture closure stage.

On a pressure-time plot of the fracture closure phase, the normal stress can then be estimated from the transitional point between gradual pressure decline and linear decline. In a plot of flow vs. pressure, a $q P$-plot, the same pressure can be found by picking the transitional point between a gradual to a linear trend when flow- and pressure data are plotted for the fracture closure phase. This interpretation can be linked to the idea of system stiffness, originally proposed by Raaen et al. (2001), where the slope of the pressure-time graph observed prior to fracture closure represents the less stiff system associated with an open fracture, and the succeeding, steeper, linear pressure decline represents the system stiffness when the fracture is closed, as discussed in further detail in Sect. 5.2. The same way of reasoning has been presented by Thörn et al. (2015), who proposed that stiffness difference also could be associated with the matedness of fracture surfaces, where poorly fitted surfaces have low normal stiffness whilst well-mated fractures large normal stiffness. This difference in matedness might explain the observed reduction of system stiffness represented by the difference of slope between the pre-opening and post-closure stages for all four hydraulic jacking tests, see Fig. 12. The same mechanism can also explain the observed distinct difference in fracture opening pressure between tests 004-A and 004-B, which would otherwise be expected to be similar since the pressurization rate and confining pressures were identical. This assumed change in matedness might have been caused by minor shear dislocation of the fracture during testing, or by particles dislodged from the fracture surface during the hydraulic jacking, as has been suggested by Chitrala et al. (2011).

\subsection{Determination of Fracture Closure}

Fracture closure following hydraulic stimulation can be described as a three-stage process (Hayashi and Haimson 1991): stage 1, hinge-like fracture closure, i.e. closure by width reduction but at constant fracture length; stage 2, fracture starting to close at the tip and gradual fracture length reduction, and ultimately; stage 3 , where the fracture closes fully, or to its residual aperture depending on the fracture characteristics, see Fig. 17. This understanding of fracture closure behaviour has been used by Raaen et al. (2001) to explain the different stages of pressure decline during flow-back tests. Referring to Fig. 17, the essence of their interpretative model is that the initial linear pressure decay (stage 1) represents the system stiffness when the fracture is

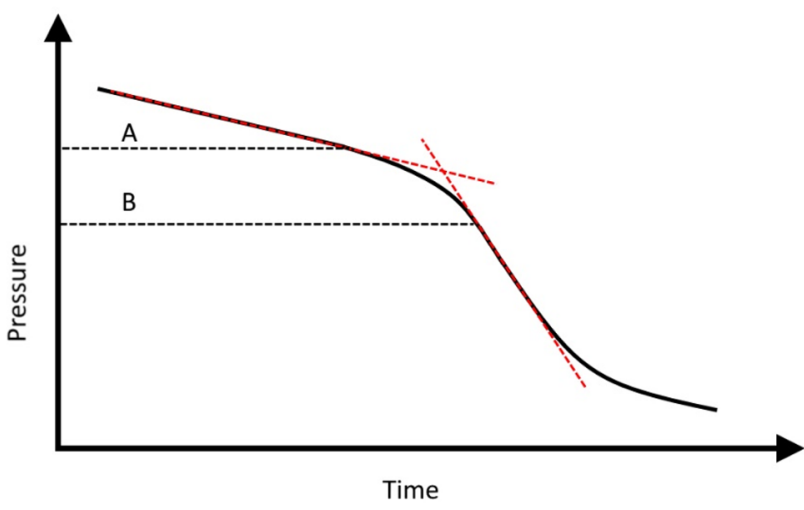

Fig. 17 The three stages of fracture closure shown in an idealized pressure-time plot for the step-down stage of a RSRT: first, a linear pressure decline is observed when the fracture closes in a hinge-like manner, until point $\mathrm{A}$, where deviation from linearity indicates onset of fracture closure (asperities start to touch). As the fracture closes, it will progressively increase its stiffness until point $B$, where the fracture is closed. Modified after Savitski and Dudley (2011)

open, and when the asperities of the fracture surfaces start to touch (point A), there is a gradual increase in system stiffness (stage 2), until the fracture finally closes (point B) and a new linear pressure decay is observed (stage 3), representing the system stiffness with a closed fracture.

There has been some debate as to which of the two inflection points best represents fracture closure and corresponding fracture normal stress. Arguments have been put forward for picking the point of first inflection $(A)$ (Raaen et al. 2001), picking the intersection point of the lines drawn through the two linear segments (Plahn et al. 1997) and (Jung et al. 2016), or picking the lower inflection point (B) (Shlyapobersky 1989) and (Savitski and Dudley 2011).

In the experimental data, it has been found that the pressure at the lower inflection point corresponds reasonably well with the expected normal stress, as discussed in Sect. 4.3.1. An initial linear pressure decline, corresponding to stage 1 of Fig. 17, cannot be identified in the pressure-time graphs of tests 001-A and 004-A, but is partially visible for tests 005-A and 006-A, as can be seen in Fig. 12. This might suggest that picking the upper inflection point would overestimate the normal stress.

Picking the inflection points presented in Fig. 12 was done by fitting straight lines to the linear trend of each graph, to find the point of deviation. This approach, common in field applications, will introduce some subjectivity to the fracture closure determination. To reduce this subjectivity, plots of the time derivative of pressure versus time have been used, since the time derivative of pressure is linear when the system stiffness is constant, and stiffness changes thus may be detected from such plots (Raaen et al. 2001). However, since the pressure-time graphs are quasi-linear, the derivative plots offer only limited guidance on finding the exact 

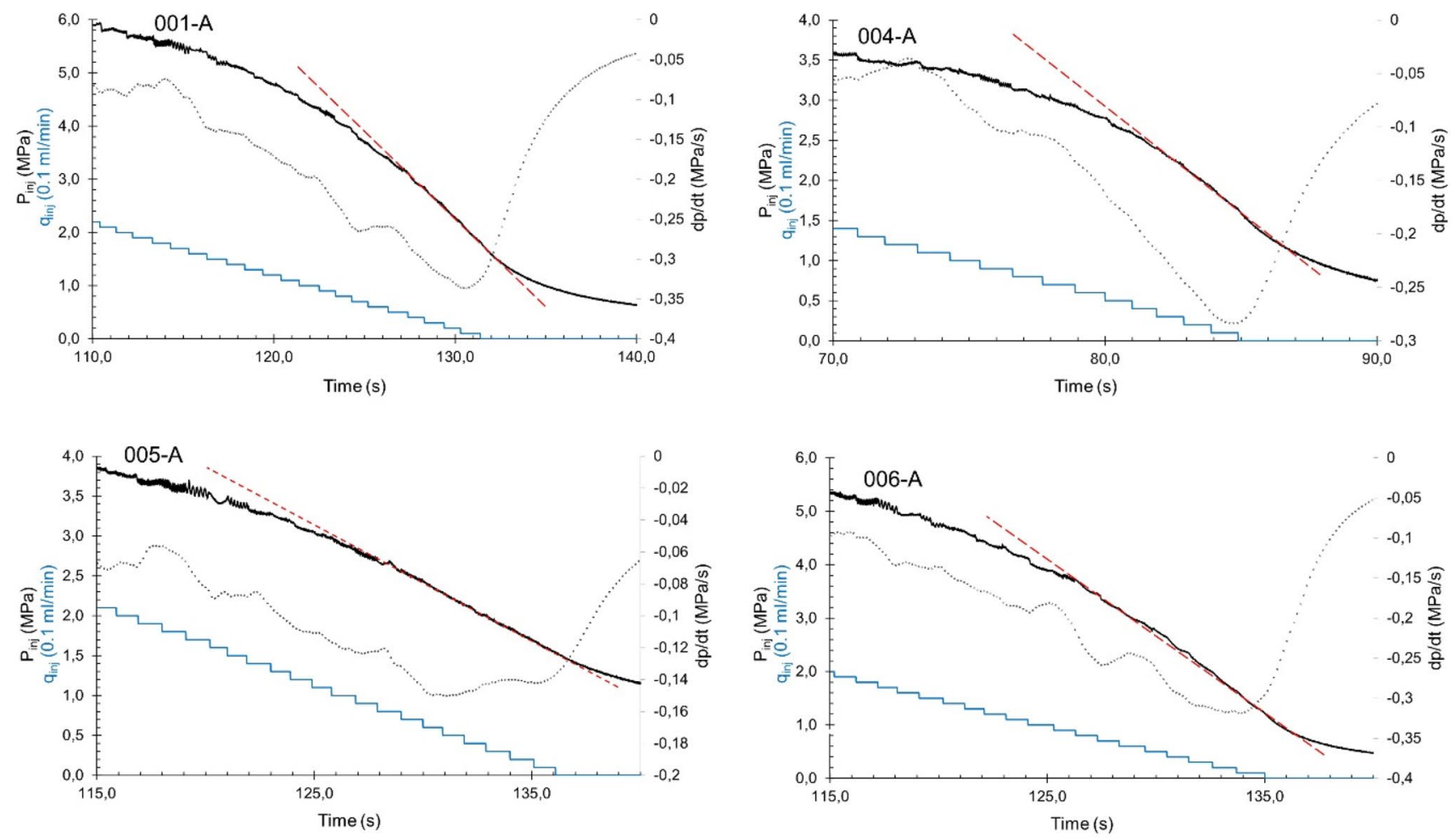

Fig. 18 Injection pressure variation as a function of time and flowrate, including the time derivative of the pressure (dotted line) for the closure stage of tests 001-A, 004-A, 005-A and 006-A

inflection points, as no distinct breaks in the derivative plot can be found, see Fig. 18.

The authors believe that simple graphical methods for finding the inflection point, as illustrated in Figs. 12 and 14, are well suited for the purpose as they can provide estimates of fracture normal stresses that are reasonably accurate, whilst at the same time maintaining the intended simplicity of the RSRT procedure.

\subsection{Fracture Behaviour and AE Response}

The observed link between AE response and the mechanical behaviour of the fracture represents a useful supplement to hydraulic jacking tests, potentially enabling a more robust assessment of fracture normal stresses. Similar observations of AE events associated with fracture closure have been reported by several authors (Ishida et al. 1997, 2012; Chitrala et al. 2011; Zhuang et al. 2020). Upon investigating the reported link between $\mathrm{AE}$ activity and fracture closure Bunger et al. (2014), however, did not find the same correlation during unconfined laboratory experiments, and concluded that it was not appropriate to link post shut-in $\mathrm{AE}$ events with fracture closure. From our experiments, we firmly believe that such a link does exists, and that the reported absence of AE events might be linked to the unconfined conditions of which the test was performed.

The AE event rate response does not seem to be sufficiently distinct to assess the exact moment of fracture closure, and the fracture normal stress, hence, could not be assessed from AE data alone. It is believed that the indistinct $\mathrm{AE}$ response primarily is caused by the repeated dynamic contact of fracture wall asperities, caused by the dilated fractures response to the incremental flow steps. In addition, when fluid percolates through the fracture there can be local and temporal pressure fluxes caused by repeated cycles of pressure build-up and deflation. Still, AE monitoring during hydraulic jacking tests is considered highly promising, not only for identifying the moment of fracture closure, but also to delineate the orientation of the stimulated fracture, as originally suggested by Tanaka et al. (1997), and later demonstrated by (Zang et al. 2017). The "tail" of AE events observed long after the fracture appears to be closed is believed to be associated with the further, slow, closure of the fracture as water without hydraulic connection to the test section slowly is drained from the fracture. 


\subsection{Relevance to Field-Scale Stress Measurements}

Investigation of hydraulic fracturing processes at laboratory scale requires proper scaling to adequately represent field conditions (De Pater and Weijers 1994). Results obtained from laboratory-scale hydraulic jacking experiments are, however, more easily transferred to field conditions as no material strength parameters, such as fracture toughness need to be considered. Still, some adaptions must be made when upscaling the proposed test procedure to field conditions, mainly related to the equipment used during testing, as will be discussed in the following.

First, is it required that the pump can be operated in flowcontrol mode without significant pressure pulses, so that the test sequence can be programmed to the desired flow steps and that fluid flow and pressure can be accurately measured and logged. A potential limiting factor for hydraulic jacking tests may be represented by the flow capacity of the pump, especially in the case of high rock mass permeability. One example is what was experienced at the Kihansi HPP in Tanzania, where measurements performed in an extensional tectonic regime required a pump capable of delivering 100 1/min at $20 \mathrm{MPa}$ (Dahlø et al. 2003). Sufficient pumping capacity has also been addressed by Benson (1989), and the practical reason is clear: should the pumping capacity be too low for a given test hole, no pressure build-up can be achieved, and hence, no meaningful estimate of fracture normal stresses can be made. A common practical mitigating measure to this problem is simply to shorten the test section by deeper packer placements, or alternatively omitting holes with too high permeability altogether, moving to the next. Should still the permeability be too high can either shorter holes be drilled, or viscosity adjustments made to the injection fluid (Dr. B. Buen, personal communication May 2019).

During the laboratory experiments described in this paper, it has been found that the native $1 \mathrm{kHz}$ sampling rate of the pressure transmitters should be downsampled to reduce noise, in line with the findings of Kakurina et al. (2020). By looking at the data at various degrees of downsampling, it seems that $100 \mathrm{~Hz}$ sampling rate would be optimal, and that sampling rates lower than $10 \mathrm{~Hz}$ should be avoided, since important details are lost. Therefore, we recommend sampling rates ranging from 10 to $100 \mathrm{~Hz}$ for fieldscale hydraulic jacking tests. The transmitter itself should ideally be located as close to the test section as possible to minimize the effect of friction losses, especially at high flow rates (Wandke and Cooper 2016).

To enhance the sensitivity to minor changes in system stiffness during hydraulic testing it has been suggested to minimize the fluid volume used during testing, and to use a piping system with high stiffness (Ito et al. 2006). Even though this theoretically can enhance the sensitivity, it is hard to realize in the field due to the minimum requirements of the borehole dimensions, causing the bulk of the fluid volume to be in the open-hole section and only a fraction in the tubing/piping.

In the introduction, it was argued that distributed measurements along the entire length of a pressure tunnel can provide better insight regarding stress variability, and thus reduce the risk of hydraulic failure. To enable timely adjustments of the tunnel design (if stresses are too low), these measurements should be performed not too far behind the advancing excavation front. This requires that the measurements can be made quite regularly, such that they in a sense are an integral part of the tunnelling activities-and not as per current practice an occasional specialist activity requiring planned stops in other tunnelling activities. Performing standardized HF/HTPF tests regularly along the pressure tunnel would be prohibitively costly, due to the specialist nature of such tests. Though relatively cost-effective, the simplified hydraulic jacking tests commonly used as an alternative to HF/HTPF tests are somewhat impractical due to the long test duration (typically $\sim 1-2 \mathrm{~h}$ for each test), causing undesirable hindrance to other tunnelling activities. The semi-automated and rapid nature of the proposed RSRT enable highly efficient tests (minutes, rather than hours), and since operator bias can be minimized-there is no strict requirement for specialist crews.

\section{Conclusions}

A simplified hydraulic jacking test variant, termed the rapid step-rate tests, has been proposed as an alternative to the commonly adopted methods to assess the magnitude of minimum principal stress for the final design of unlined pressure tunnels. The ability of this test to assess the magnitude of normal stress acting across fractures in rock has been confirmed by laboratory experiments, demonstrating good agreement between measured and anticipated values of normal stress. The experimental data suggest that interpretation of test data should be made based on the fracture closure phase only, as data from the fracture-opening phase indicate fracture-opening pressures both much higher and lower than the anticipated magnitude of normal stress.

AE monitoring during hydraulic jacking tests has proven a valuable tool for delineating the fracture orientation, and a clear correlation between fracture closure and AE activity has been demonstrated. The exact moment of fracture closure has, however, not been possible to detect in the $\mathrm{AE}$ data alone.

To further assess the field applicability of the proposed Rapid Step-Rate Test, a field verification is needed. Some initial field tests have already been performed, the 
preliminary results of which have been used when preparing the RSRT procedure. Additional field tests are under planning.

The link between fracture closure and $\mathrm{AE}$ event rate has turned out as a highly promising path in laboratory testing and should be further investigated for use in the field. By pursuing the original idea suggested by Tanaka et al. (1997) with a downhole AE-sonde deployed in the same hole as that which is being tested, improved detection of AE events might be attained. This, in turn, might enable linking the moment of fracture closure, detected from AE data, with the fracture orientation, also found from AE data-potentially providing more accurate rock stress estimation from hydraulic jacking and fracturing tests.

Acknowledgements The Research Council of Norway (NFR) is acknowledged for financing this ongoing research through the Norwegian Research Centre for Hydropower Technology (HydroCen). The authors would like to thank Professor Marte Gutierrez and PhD candidate Ketan Arora for sharing their experience with the design and use of their true-triaxial test rig during our visit to the Colorado School of Mines in the U.S. The excellent craftsmanship demonstrated by Magne Sollie, constructing the test frame, and his practical and efficient solutions to certain initial design challenges is also highly appreciated. Lars Nord $\varnothing$ is thanked for his curiosity and interest of hydraulic jacking and $\mathrm{AE}$ monitoring, resulting in valuable contributions in the laboratory through his MSc-project. Finally, we would like to express our gratitude to the laboratory staff at the Department of Geoscience and Petroleum at NTNU: Noralf, Steffen, Roger, Terje, Gunnar, Jon, and in particular, Torkjell Breivik for his considerable effort in developing the software needed for the monitoring and control of our experiments.

Funding Open access funding provided by NTNU Norwegian University of Science and Technology (incl St. Olavs Hospital - Trondheim University Hospital).

\section{Declarations}

Conflict of interest The authors confirm that there are no known conflicts of interest associated with the publication of this article, and that are no financial or non-financial interests that has affected the outcome of this work.

Open Access This article is licensed under a Creative Commons Attribution 4.0 International License, which permits use, sharing, adaptation, distribution and reproduction in any medium or format, as long as you give appropriate credit to the original author(s) and the source, provide a link to the Creative Commons licence, and indicate if changes were made. The images or other third party material in this article are included in the article's Creative Commons licence, unless indicated otherwise in a credit line to the material. If material is not included in the article's Creative Commons licence and your intended use is not permitted by statutory regulation or exceeds the permitted use, you will need to obtain permission directly from the copyright holder. To view a copy of this licence, visit http://creativecommons.org/licenses/by/4.0/.

\section{References}

Amadei B, Stephansson O (1997) Rock stress and its measurement. Springer, Berlin. https://doi.org/10.1007/978-94-011-5346-1

Benson RP (1989) Design of unlined and lined pressure tunnels. Tunn Undergr Space Technol 4:155-170. https://doi.org/10.1016/08867798(89)90049-7

Berkey CP, Sanborn JF (1922) Engineering geology of the Catskill water supply. Trans Am Soc Civ Eng 48:1029-1595

Bredehoeft JD, Wolff RG, Keys WS, Shuter E (1976) Hydraulic fracturing to determine the regional in situ stress field, Piceance Basin, Colorado. Geol Soc Am Bull 87:250

Brekke TL, Ripley BD (1987) Design guidelines for pressure tunnels and shafts. University of California, Berkeley

Broch E, Dahlø TS, Hansen SE (1997) Hydraulic jacking tests for unlined high pressure tunnels. In: Broch E, Lysne DK, Flatabø N, Helland-Hansen E (eds) Hydropower '97. A. A. Balkema, Rotterdam, pp 581-611

Bunger AP, Kear J, Dyskin AV, Pasternak E (2014) Interpreting postinjection acoustic emission in laboratory hydraulic fracturing experiments. In: Paper presented at the 48th US rock mechanics/ geomechanics symposium, Minneapolis, Minnesota, 2014.8.18

Cheung LS, Haimson BC (1989) Laboratory study of hydraulic fracturing pressure data-how valid is their conventional interpretation? Int J Rock Mech Min Sci Geomech Abstr 26:595-604. https://doi. org/10.1016/0148-9062(89)91440-X

Chitrala Y, Moreno C, Sondergeld C, Rai C (2011) Microseismic and microscopic analysis of laboratory induced hydraulic fractures. In: Paper presented at the Canadian Unconventional Resources Conference, Calgary, Canada, 15-17 November

Cornet F (1993) 15-The HTPF and the integrated stress determination methods. In: Hudson JA (ed) Comprehensive rock engineering, vol 3. Pergamon, Oxford, pp 413-432. https://doi.org/10.1016/ B978-0-08-042066-0.50021-5

Cornet FH (2016) Hydraulic testing in boreholes for a robust and complete in situ stress determination. In: Paper presented at the ISRM international symposium on in-situ rock stress, Tampere, Finland, 2016.1.1

Cornet FH, Valette B (1984) In situ stress determination from hydraulic injection test data. J Geophys Res 89:11527-11537. https://doi. org/10.1029/JB089iB13p11527

Dahlø T, Evans KF, Halvorsen A, Myrvang A (2003) Adverse effects of pore-pressure drainage on stress measurements performed in deep tunnels: an example from the Lower Kihansi hydroelectric power project, Tanzania. Int J Rock Mech Min Sci 40:65-93. https://doi. org/10.1016/S1365-1609(02)00114-4

De Pater CJ, Weijers L (1994) Experimental verification of dimensional analysis for hydraulic fracturing. SPE Prod Facil. https://doi.org/ 10.2118/24994-PA

Doe TW, Korbin GE (1987) A comparison of hydraulic fracturing and hydraulic jacking stress measurements. In: Paper presented at the the 28th US symposium on rock mechanics (USRMS), Tucson, Arizona, 1987.1.1

Economides MJ, Nolte KG (2000) Reservoir stimulation. Wiley, Chichester

Evans KF, Scholz CH, Engelder T (1988) An analysis of horizontal fracture initiation during hydrofrac stress measurements in granite at North Conway, New Hampshire. Geophys J 93:251-264. https://doi.org/10.1111/j.1365-246X.1988.tb02000.x

Felsenthal M (1974) Step-rate tests determine safe injection pressure on floods. Oil Gas J 72:49-55

Frash L, Gutierrez M, Hampton J (2015) Laboratory-Scale-model testing of well stimulation by use of mechanical-impulse hydraulic fracturing. SPE J 20:536-549. https://doi.org/10.2118/ 173186-PA0 
Haimson B (1992) Designing pre-excavation stress measurements for meaningful rock characterization. In: Paper presented at the ISRM Eurock '92 symposium on rock characterization, London, 4-17 September

Haimson BC, Cornet FH (2003) ISRM suggested methods for rock stress estimation-Part 3: hydraulic fracturing (HF) and/or hydraulic testing of pre-existing fractures (HTPF). Int J Rock Mech Min Sci 40:1011-1020. https://doi.org/10.1016/j.ijrmms. 2003.08.002

Haimson B, Fairhurst C (1969) In-situ stress determination at great depth by means of hydraulic fracturing. In: Paper presented at the The 11th US symposium on rock mechanics (USRMS), Berkeley, California, 1969.1.1.

Haimson BC, Zhao Z (1991) Effect of borehole size and pressurization rate on hydraulic fracturing breakdown pressure. In: Paper presented at the the 32nd US symposium on rock mechanics (USRMS), Norman, Oklahoma, 1991.1.1

Hampton J, Gutierrez M, Matzar L, Hu D, Frash L (2018) Acoustic emission characterization of microcracking in laboratory-scale hydraulic fracturing tests. J Rock Mech Geotech Eng. https://doi. org/10.1016/j.jrmge.2018.03.007

Hartmaier HH, Doe TW, Dixon G (1998) Evaluation of hydrojacking tests for an unlined pressure tunnel. Tunn Undergr Space Technol 13:393-401. https://doi.org/10.1016/S0886-7798(98)00082-0

Hayashi K, Haimson BC (1991) Characteristics of shut-in curves in hydraulic fracturing stress measurements and determination of in situ minimum compressive stress. J Geophys Res Solid Earth 96:18311-18321. https://doi.org/10.1029/91JB01867

Huang B, Liu J (2017) Experimental investigation of the effect of bedding planes on hydraulic fracturing under true triaxial stress. Rock Mech Rock Eng 50:2627-2643. https://doi.org/10.1007/ s00603-017-1261-8

Hubbert MK, Willis DG (1957) Mechanics of hydraulic fracturing. J Pet Technol 210:153-168

Ikeda R, Tsukahara H (1982) Acoustic emissions detected by hydrophone during hydraulic fracturing stress measurement. In: Paper presented at the workshop XVII-hydraulic fracturing stress measurements, California, 2-5 December

Injeksjonsteknikk (2017) Testresultater fra jekketesting ved Verma kraftverk pel 50-60 (In Norwegian). Unpublished field data

Ishida T (2001) Acoustic emission monitoring of hydraulic fracturing in laboratory and field. Constr Build Mater 15:283-295. https:// doi.org/10.1016/S0950-0618(00)00077-5

Ishida T, Chen Q, Mizuta Y (1997) Effect of injected water on hydraulic fracturing deduced from acoustic emission monitoring. Pure Appl Geophys 150:627-646. https://doi.org/10.1007/s000240050 096

Ishida T, Aoyagi K, Niwa T, Chen Y, Murata S, Chen Q, Nakayama $Y$ (2012) Acoustic emission monitoring of hydraulic fracturing laboratory experiment with supercritical and liquid $\mathrm{CO}_{2}$. Geophys Res Lett. https://doi.org/10.1029/2012GL052788

Ito T, Evans K, Kawai K, Hayashi K (1999) Hydraulic fracture reopening pressure and the estimation of maximum horizontal stress. Int J Rock Mech Min Sci 36:811-826. https://doi.org/10.1016/ S0148-9062(99)00053-4

Ito T, Igarashi A, Kato H, Ito H, Sano O (2006) Crucial effect of system compliance on the maximum stress estimation in the hydrofracturing method: theoretical considerations and field-test verification Earth. Planets Space 58:963-971. https://doi.org/10.1186/BF033 52601

Jung H, Sharma MM, Cramer DD, Oakes S, McClure MW (2016) Reexamining interpretations of non-ideal behavior during diagnostic fracture injection tests. J Petrol Sci Eng 145:114-136. https://doi. org/10.1016/j.petrol.2016.03.016

Kakurina M, Guglielmi Y, Nussbaum C, Valley B (2020) Situ direct displacement information on fault reactivation during fluid injection. Rock Mech Rock Eng. https://doi.org/10.1007/ s00603-020-02160-w

Lizak KF, Bartko KM, Self JF, Izquierdo GA, Al-Mumen M (2006) New analysis of step-rate injection tests for improved fracture stimulation design. In: SPE international symposium and exhibition on formation damage control, SPE-98098-MS. https://doi. org/10.2118/98098-ms

Londe P, Sabarly F (1966) La distribution des perméabilités dans la fondation des barrages voûtes en fonction du champ de contrainte. In: Paper presented at the 1st ISRM Congress, Lisbon, Portugal, 1966.1.1

Merritt AH (1999) Geologic and geotechnical considerations for pressure tunnel design. In: Paper presented at the geo-engineering for underground facilities, University of Illinois, 13-17 June

Nolte KG (1982) Fracture design considerations based on pressure analysis. In: SPE cotton valley symposium, SPE-10911-MS. https://doi.org/10.2118/10911-ms

Nordal S, Grøv E, Emdal A, L'Heureux JS (2018) Skredene i Tosbotn, Nordland 1. og 2. april 2016. Rapport fra undersøkelsesgruppe satt ned av Nordland Fylkeskommune. NTNU, Trondheim (In Norwegian)

Ødegaard H, Nilsen B (2018) Engineering geological investigation and design of transition zones in unlined pressure tunnels. In: Paper presented at the ISRM international symposium-10th Asian rock mechanics symposium, Singapore, 29.10-2.11 2018

Philippe V, Eda Q, Milton Assis K, Tom J, Mehmet E (2019) ISRM suggested method for the Lugeon Test. Rock Mech Rock Eng 52:4155-4174. https://doi.org/10.1007/s00603-019-01954-x

Plahn SV, Nolte KG, Miska S (1997) A quantitative investigation of the fracture pump-in/fiowback test. SPE J 12:20-27. https://doi. org/10.2118/30504-pa

Raaen AM, Skomedal E, Kjørholt H, Markestad P, Økland D (2001) Stress determination from hydraulic fracturing tests: the system stiffness approach. Int J Rock Mech Min Sci 38:529-541. https:// doi.org/10.1016/S1365-1609(01)00020-X

Rancourt AJ (2010) Guidelines for preliminary design of unlined pressure tunnels. PhD, McGill University

Rasouli V (2013) A true triaxial stress cell (TTSC) used for simulations of real field operations in the lab. In: Kwasniewski M (ed) True triaxial testing of rocks, vol 4. CRC Press, London, pp 311-319

Rutqvist J, Stephansson O (1996) A cyclic hydraulic jacking test to determine the in situ stress normal to a fracture. Int J Rock Mech Min Sci Geomech Abstr 33:695-711. https://doi.org/10.1016/ 0148-9062(96)00013-7

Rutqvist J, Stephansson O (2003) The role of hydromechanical coupling in fractured rock engineering. Hydrogeol J 11:7-40. https:// doi.org/10.1007/s10040-002-0241-5

Savitski AA, Dudley JW (2011) Revisiting microfrac in-situ stress measurement via flow back-a new protocol. In: SPE annual technical conference and exhibition, SPE-147248-MS. https:// doi.org/10.2118/147248-ms

Schjerven H (1921) Tryktunnelen ved Herlandsfossen. Den Norske Ingeniør- og Arkitekt-forening og Den Polytekniske Forening, Oslo (In Norwegian)

Shi L, Li B, Bai Q, Feng X (2013) Numerical analysis of loading boundary effects in Mogi-type true triaxial tests. In: Kwaśniewski M, Li X, Takahashi M (eds) Geomechanics research series, vol 4. CRC Press, London, pp 19-33

Shlyapobersky J (1989) On-site interactive hydraulic fracturing procedures for determining the minimum in situ stress from fracture closure and reopening pressures. Int J Rock Mech Min Sci Geomech Abstr 26:541-548. https://doi.org/10.1016/01489062(89)91432-0

Singh PK, Agarwal RG, Krase LD (1987) Systematic design and analysis of step-rate tests to determine formation parting pressure. In: 
Paper presented at the SPE annual technical conference and exhibition, Dallas, Texas, 1987/1/1/

Smith MB, Montgomery CT (2014) Hydraulic fracturing. Emerging trends and technologies in petroleum engineering. CRC Press, Hoboken

Stanchits S, Surdi A, Gathogo P, Edelman E, Suarez-Rivera R (2014) Onset of hydraulic fracture initiation monitored by acoustic emission and volumetric deformation measurements. Rock Mech Rock Eng 47:1521-1532. https://doi.org/10.1007/s00603-014-0584-y

Tanaka M, Kuwabara K, Honma M, Ishida T, Mizuta Y, Kanagawa T (1997) Determination of crack direction in hydraulic fracutring by borehole acoustic emission sonde. In: Paper presented at the rockbursts and seismisicty in mines, Kraków, Poland, 11-14 August

Thörn J, Ericsson LO, Fransson Å (2015) Hydraulic and hydromechanical laboratory testing of large crystalline rock cores. Rock Mech Rock Eng 48:61-73. https://doi.org/10.1007/s00603-013-0538-9

USACE (1997) Engineering and design. Tunnels and shafts in rock. U.S. Army Corps of Engineers, Washington

Wandke L, Cooper K (2016) Application and analysis of step-rate testing to determine fracture pressure in injection wells. In: Underground injection control conference, Denver, CO, 23-25 February 2016. Ground Water Protection Council, pp 1-23

Warren WE, Smith CW (1985) In situ stress estimates from hydraulic fracturing and direct observation of crack orientation. J Geophys Res 90:6829-6839. https://doi.org/10.1029/JB090iB08p06829
Zang A et al (2017) Hydraulic fracture monitoring in hard rock at 410 $m$ depth with an advanced fluid-injection protocol and extensive sensor array. Geophys J Int 208:790-813. https://doi.org/10.1093/ gji/ggw430

Zhang G-Q, Fan T (2014) A high-stress tri-axial cell with pore pressure for measuring rock properties and simulating hydraulic fracturing. Measurement 49:236-245. https://doi.org/10.1016/j.measu rement.2013.11.001

Zhuang L et al (2020) Laboratory true triaxial hydraulic fracturing of granite under six fluid injection schemes and grain-scale fracture observations. Rock Mech Rock Eng 53:4329-4344. https://doi. org/10.1007/s00603-020-02170-8

Zoback MD (2007) Reservoir geomechanics. Cambridge University Press, Cambridge

Zoback MD, Kohli AH (2019) Unconventional reservoir geomechanics: shale gas, tight oil and induced seismicity. Cambridge University Press, Cambridge

Publisher's Note Springer Nature remains neutral with regard to jurisdictional claims in published maps and institutional affiliations. 